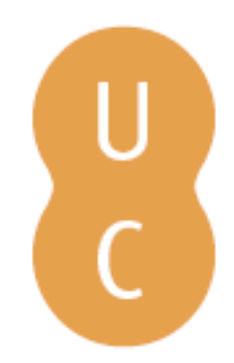

\title{
nombalina
}

\section{Brasileiros na reforma pombalina: criando novos caminhos da ciência entre Portugal e o Brasil}

\author{
Autor(es): $\quad$ Martins, Décio Ruivo \\ Publicado por: Imprensa da Universidade de Coimbra \\ URL \\ persistente: URI:http://hdl.handle.net/10316.2/30710 \\ DOI: $\quad$ DOI:http://dx.doi.org/10.14195/978-989-26-0308-7_3 \\ Accessed : $\quad$ 26-Apr-2023 04:44:26
}

A navegação consulta e descarregamento dos títulos inseridos nas Bibliotecas Digitais UC Digitalis, UC Pombalina e UC Impactum, pressupõem a aceitação plena e sem reservas dos Termos e Condições de Uso destas Bibliotecas Digitais, disponíveis em https://digitalis.uc.pt/pt-pt/termos.

Conforme exposto nos referidos Termos e Condições de Uso, o descarregamento de títulos de acesso restrito requer uma licença válida de autorização devendo o utilizador aceder ao(s) documento(s) a partir de um endereço de IP da instituição detentora da supramencionada licença.

Ao utilizador é apenas permitido o descarregamento para uso pessoal, pelo que o emprego do(s) título(s) descarregado(s) para outro fim, designadamente comercial, carece de autorização do respetivo autor ou editor da obra.

Na medida em que todas as obras da UC Digitalis se encontram protegidas pelo Código do Direito de Autor e Direitos Conexos e demais legislação aplicável, toda a cópia, parcial ou total, deste documento, nos casos em que é legalmente admitida, deverá conter ou fazer-se acompanhar por este aviso.

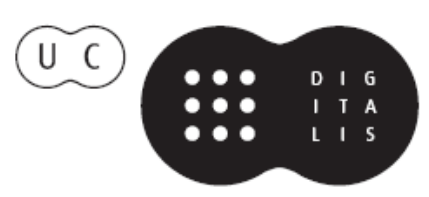



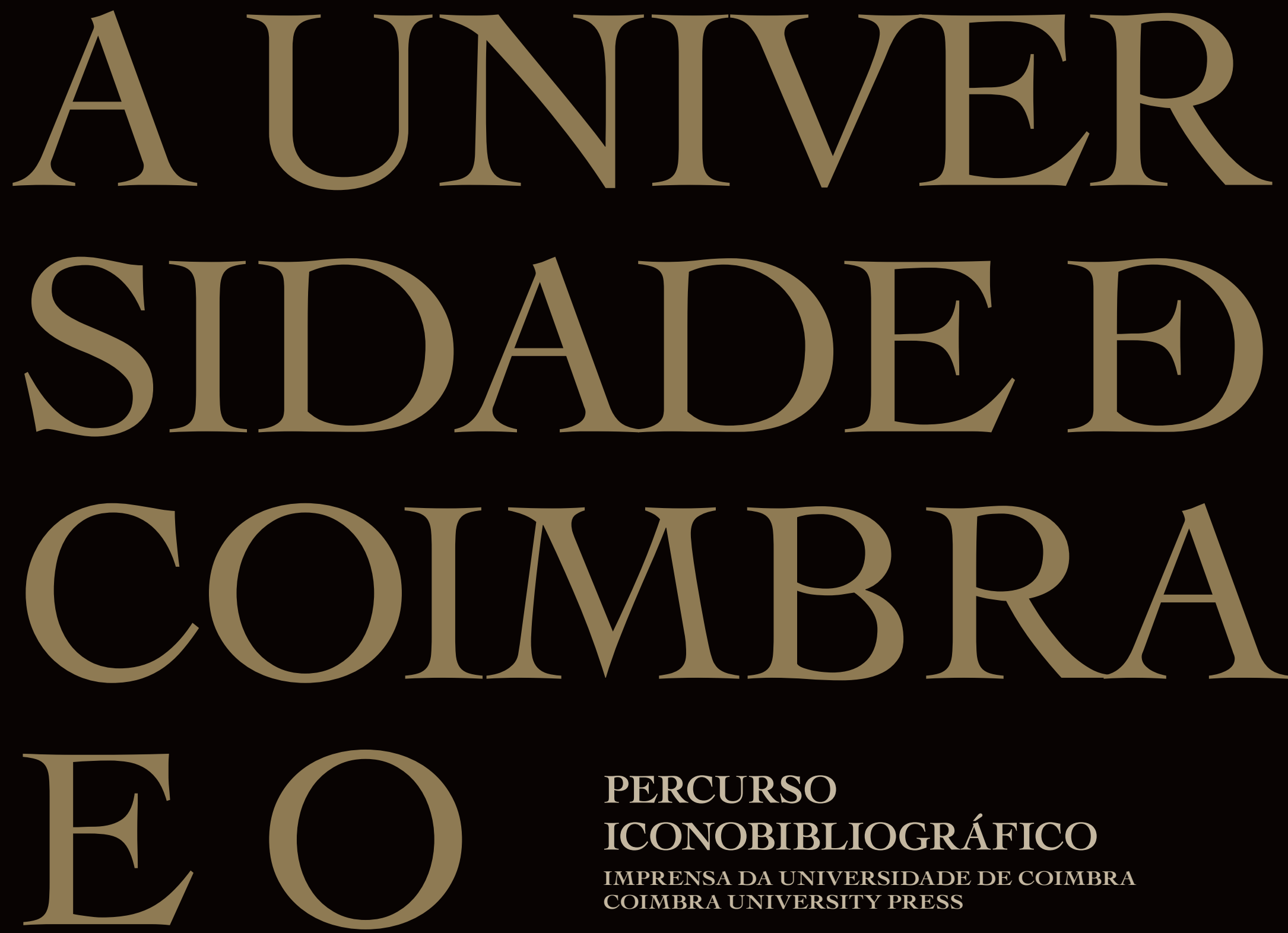

\section{PERCURSO}

\section{ICONOBIBLIOGRÁFICO}

IMPRENSA DA UNIVERSIDADE DE COIMBRA

COIMBRA UNIVERSITY PRESS

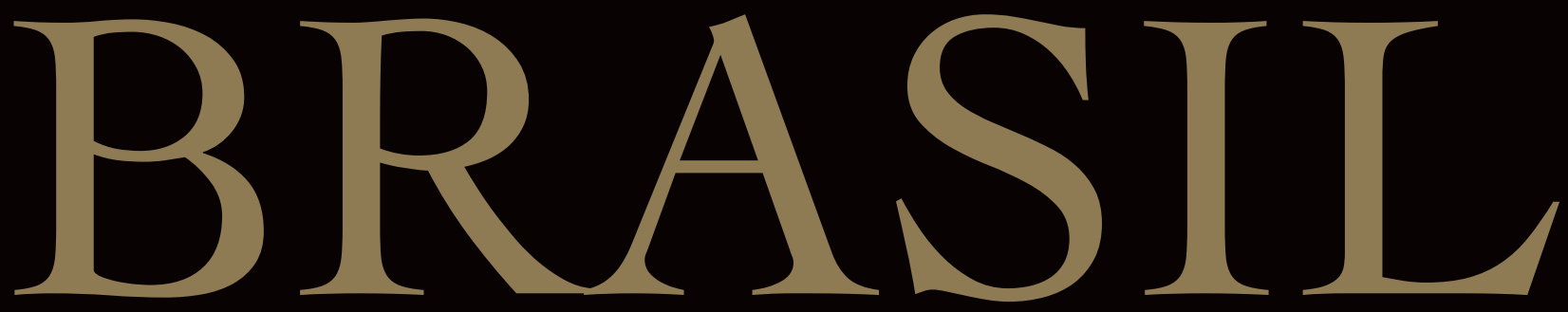


EDIÇÃO

Imprensa da Universidade de Coimbra

EMAIL: IMPRENSAUC@CI.UC.PT

URL: HTTP://WWW.UC.PT/IMPRENSA_UC

VENDAS ONLINE: HTTP://WWW.LIVRARIADAIMPRENSA.COM

Coordenação Científica

José Pedro Paiva

José Augusto Cardoso Bernardes

Textos

Joño Gabriel Silva

José Pedro Paiva

José Augusto Cardoso Bernardes

Joaquim Romero Magalhães

Décio Ruivo Martins

Fernando Ramos

Lúcio CunHa

Rui JaCINTO

JoÃo Arriscado Nunes

Maria Aparecida Ribeiro

Investigação e Conteúdos das Fichas Catalográficas

A.E. Maia do Amaral (Bguc)

Ana Maria Leitão Bandeira (auc)

Créditos Fotográficos

Miguel Pacheco/Redinteg Lda. (Digitalizações de livros e documentos)

Gilberto Pereira (exemplares zoológicos)

Pedro Casaleiro (exemplar etnográfico)

Tiago Maia/AuC (PeÇas museológicas - Ma)

Delfim Ferreira (arquitetura)

DESIGN

António Barros

INFOGRAFIA

Carlos Costa

EXECUÇÃo GRÁFICA

NORPRINT

ISBN

978-989-26-0161-8

Depósito Legal

Obra Publicada com o Patrocínio de 

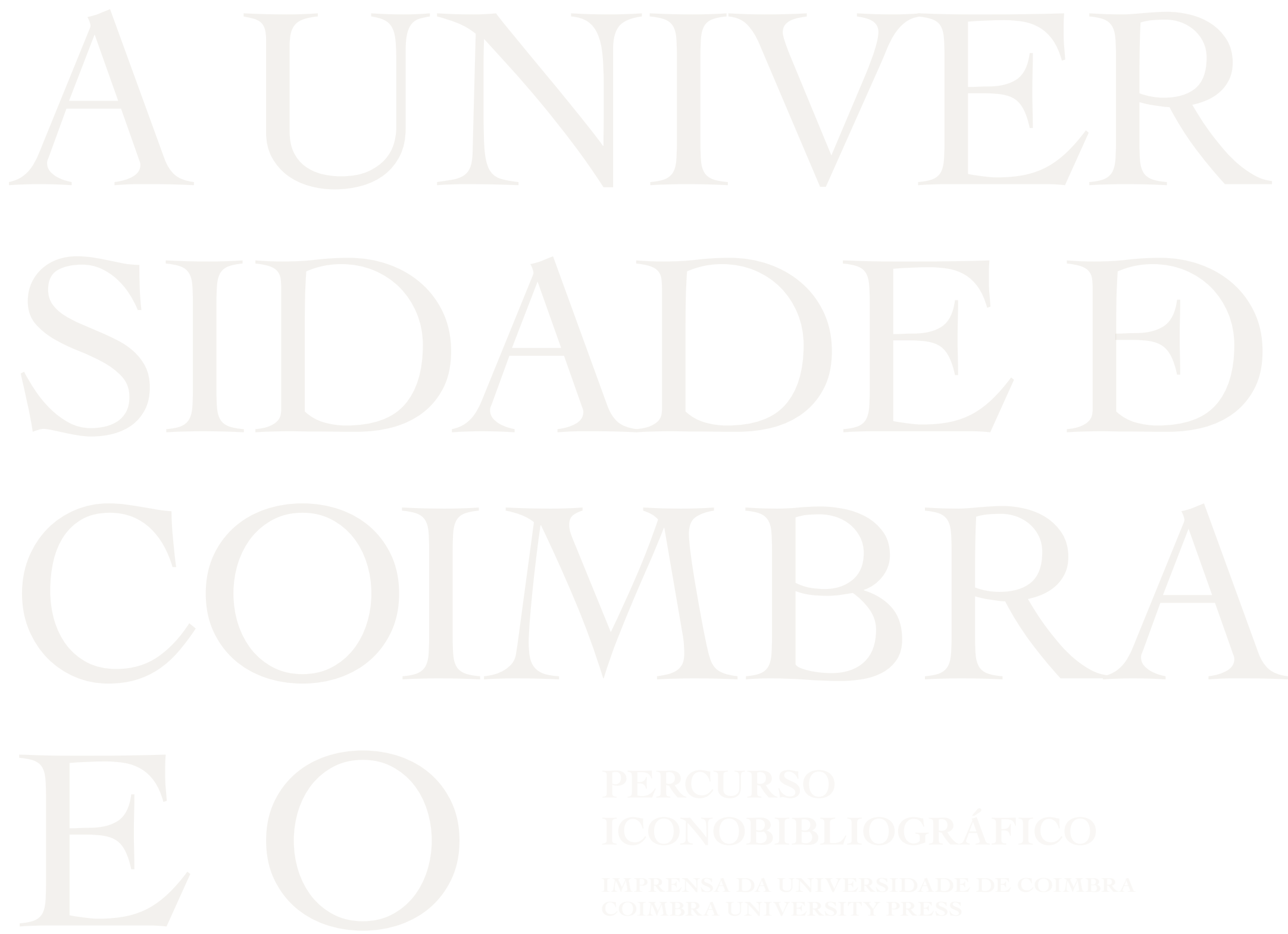

PRTOUROO
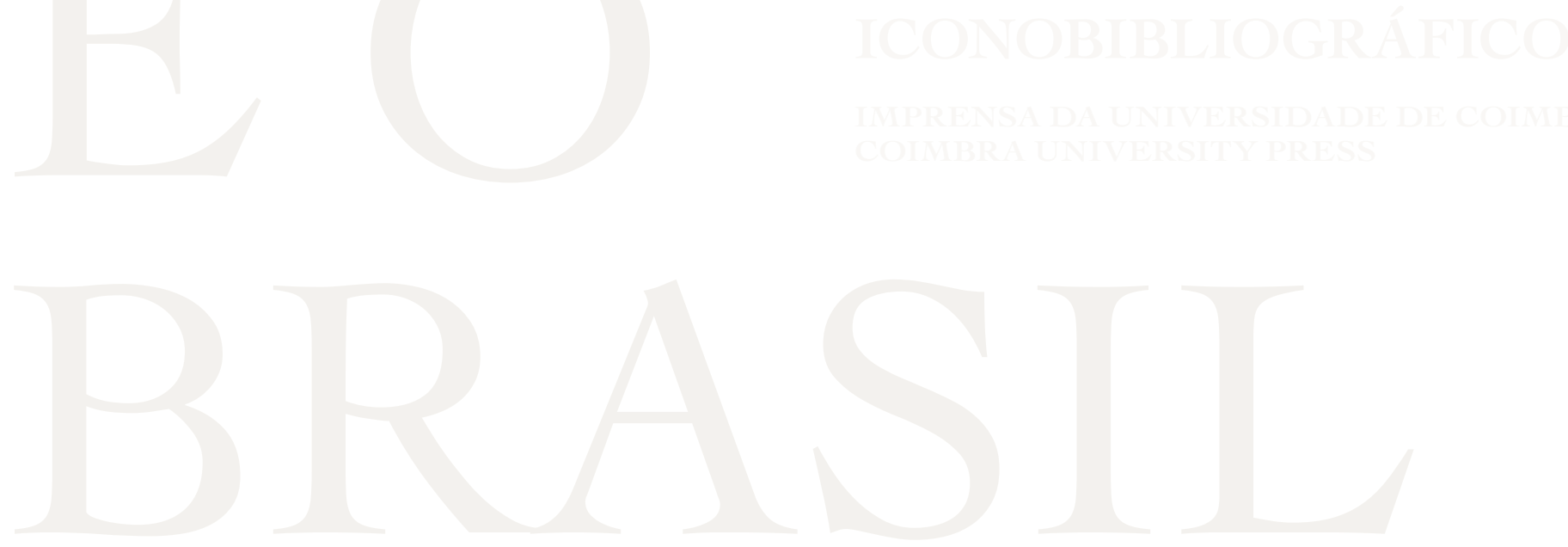
(Página deixada propositadamente em branco) 


\title{
Brasileiros na Reforma POMBAlina \\ Criando novos caminbos da Ciência entre Portugal e o Brasil
}

\author{
Décio Ruivo Martins
}





\section{$\mathrm{O}$}

ambiente político e social que se viveu em Portugal desde finais da década de cinquenta do século XVIII contribuiu para a emergência de uma grande reforma na Universidade de Coimbra (UC). Foi uma época marcada por opiniões enérgicas contra o sistema de ensino considerado decadente quando comparado com os paradigmas europeus da época. No início da década de setenta deu-se a remodelação universitária, com particular incidência no ensino das matérias científicas. Alguns nomes oriundos do Brasil estiveram na génese e consolidação desta ação renovadora. A Reforma Pombalina da Universidade impulsionou o desenvolvimento científico e técnico, que se repercutiu indelevelmente não só em Portugal, como no Brasil. Após a criação das Faculdades de Filosofia e de Matemática, em 1772, Coimbra passou a ser o destino preferencial de sucessivas gerações de estudantes brasileiros que demandavam a Europa. Também a Faculdade de Medicina renovada no período pombalino contribuiu para o progresso das ciências médicas no universo luso-brasileiro. No início do século XIX o modelo pombalino da organização universitária começou a implantar-se no Brasil Colónia. Ainda antes da independência ocorrida em 1822 aquelas Faculdades foram o modelo para a criação das primeiras escolas de ensino superior, com o empenhamento de algumas personalidades formadas na então única universidade do domínio luso. Os caminhos da ciência percorridos nos dois países até à atualidade são indissociáveis deste período de transformações na UC.

\section{Brasileiros na génese da Reforma Pombalina}

A instituição de um plano de ensino das ciências modelado pelos padrões europeus mais avançados foi uma das grandes prioridades do Reitor Reformador, D. Francisco Lemos de Faria Pereira
Coutinho, $17^{\circ}$ conde de Arganil, $52^{\circ}$ bispo de Coimbra. Lemos era natural do Brasil. Nasceu a 5 de abril de 1735, no engenho de Marapicu, pertencente ao seu pai, na freguesia de Santo António de Jacutinga, em Iguaçu, localizada na atual Baixada Fluminense, da Região Metropolitana do Rio de Janeiro. Faleceu em Coimbra a 16 de abril de 1822. Frequentou o curso de Direito Canónico na UC, tendo recebido o grau de doutor em 24 de outubro de 1754 sob a direção do seu irmão mais velho João Pereira Ramos de Azeredo Coutinho (Rio de Janeiro, 1722 - Lisboa, 12-02-1799).

Em 8 de maio de 1770 Francisco de Lemos foi nomeado Reitor da Universidade, tomando posse no dia 29 do mesmo mês, cargo que exerceu até 1779. Juntamente com o irmão, João Pereira, foi nomeado pelo governo para fazer parte da Junta de Providencia Literária, criada por Carta Régia, em 23 de dezembro de 1770. Competia-lhe identificar as causas da decadência da Universidade e propor as medidas para a sua reforma sob a inspeção do primeiro presidente da Real Mesa Censória, o arcebispo de Évora, João Cosme da Cunha (Cardeal da Cunha) e do Marquês de Pombal. Em 1771 o diagnóstico teve um título eloquente: Compendio Historico до Estado da Universidade de Coimbra no tempo da invasão dos denominados jesuitas e estragos feitos nas Sciencias e nos professores, e diretores que a regiam pelas maquinações, e publicações dos novos estatutos por elles fabricados. ${ }^{1}$

Nos documentos da Reforma da UC, a anterior organização dos estudos científicos foi criticada de uma forma inflamada. O ensino era caraterizado por uma lamentável e repreensível insciência, colocando Portugal fora do contexto do desenvolvimento científico europeu do século XVIII. No acometimento contra

1 Junta de Providência Literária - Compendio historico do estado da Universidade de Coimbra no tempo da invasão dos denominados jesuitas e dos estragos feitos nas Sciencias e nos professores, e diretores que a regiam pelas maquinações e publicações dos novos estatutos por elles fabricados. Lisboa: Na Regia Officina Typografica, 1771. 
a hegemonia da Companhia de Jesus, a responsabilidade deste alegado obscurantismo foi atribuída exclusivamente aos inacianos. De acordo com os ideólogos e conselheiros da Reforma Pombalina, a Filosofia, que até então oficialmente se ensinava, regulava-se por uma nociva influência da escolástica. Considerava-se que os temas eram tratados num ensino livresco dominado pelos arcaicos preceitos peripatéticos. Além dos jesuítas do Colégio das Artes, considerados os bastiões da escolástica, terem sido acusados de seguirem de um modo inabalável as ideias aristotélicas, também foram duramente censurados por não se isentarem de um condenável e ruinoso confronto, opondo-se a outros tipos de saber originados da praxio ou experiência científica.

Além do Cardeal da Cunha, o ambiente antijesuítico que precipitou a reforma universitária foi durante algum tempo alimentado pelo brasileiro autor do poema épico Caramuru o padre agostiniano Frei José de Santa Rita Durão, (1718/20-1784), nascido no arraial de N. S. de Nazaré do Inficionado, em Cata Preta, distrito de Mariana, Minas Gerais. Após a conclusão dos seus estudos de Filosofia e Teologia em Coimbra, realizou o exame privado em 15 de dezembro de 1756, sendo admitido como professor substituto na cadeira de Teologia. Após a tentativa de regicídio, Durão desencadeou um processo acusatório contra os jesuítas responsabilizando-os de envolvimento no atentado. ${ }^{2}$ Contudo, em 1761 mostrou-se arrependido do ataque que lhes tinha movido, rompendo com o Cardeal da Cunha, adulador e protegido de Pombal. Em consequência da vindicta que lhe foi movida pelo regime persecutório estabelecido, abandonou Portugal. Refugiou-se inicialmente em Ciudad-Rodrigo, Espanha, em 1762, tendo posteriormente passado por França e vivido em Itália.

2 BIRON, Berty R. R - Caramuru: uma transposição do Velho para o Novo Mundo. Navegações: Revista de Cultura e Literaturas de Língua Portuguesa. v. 3, n 1. 2010. p. 41-47.
Entre 1764 e 1773 foi bibliotecário na Livraria Pública Lancisiana, em Roma. Já no exílio escreveu uma Retratação com uma narrativa dos acontecimentos da época. Numa audiência com o Papa Clemente XIII apresentou a retratação, declarando o seu arrependimento pelas injúrias e calúnias contidas no sermão que pronunciara na Sé de Leiria a 9 de fevereiro de 1759 a na Pastoral que escrevera contra os jesuítas, enviada ao então Bispo de Leiria (Cardeal da Cunha - da qual este se terá apoderado e apresentado como autor). Santa Rita apenas terá regressado à $U C^{3}$ depois de o Marquês do Pombal ter deixado o governo, ocupando novamente a cátedra de Teologia, proferindo em 1778 a Oração de Sapientia intitulada Josephi Duram Theologi Conimbricensio O. E. S. A. pro annua studiorum instauratione oratio. Faleceu em Lisboa no dia 24 de janeiro de 1784.

Entretanto, a reforma da Universidade avançara imparável. ${ }^{4}$ Pronunciando-se sobre a Filosofia Escolástica, que até então se considerava ter dominado o ensino no Colégio das Artes, e defendendo uma solução que colocasse a UC ao nível das melhores escolas europeias, Francisco de Lemos afirmou o seguinte: ${ }^{5}$

Como esta Filosofia [Peripatética], que com discredito da razão por tantos Seculos ocupou este nome só servia de deslocar o entendimento dos Homens, de corromper os estudos de todas as mais Faculdades, e de uma ruina geral das Artes; as quaes não podiam adiantarse, e nem promoverse, por meio de uma Sciencia verbal, toda destituida de conhecimentos Fizicos, e verdades certas na Natureza. Pareceu à Junta

3 A data do seu regresso a Portugal continua incerta.

4 PEREIRA, Magnus Roberto de Mello; CRUZ, Ana Lúcia Rocha Barbalho da - Ciência e memória: aspetos da reforma da universidade de Coimbra de 1772. Revista de História Regional 14(1). 2009. p. 7-48.

5 LEMOS, Francisco de, - Relação Geral do Estado da Universidade de Coimbra (1777). fl. 108. 
Literaria, que devia ser abolida não só da Universidade, mas também de todas as Escolas Publicas, e Particulares, Seculares e Regulares d'estes Reynos, e Senhorios.

A ação do Reitor Reformador foi determinante para a mudança que se impunha. Na Relação Geral do Estado da Universidade de Coim$b r a^{6}$ fundamentou a necessidade nos estudos universitários de um curso onde a Filosofia Natural fosse abordada numa dimensão consentânea com os avanços científicos da época. A Universidade deveria acompanhar os mais recentes avanços da ciência, e ser ela própria um importante fator para o desenvolvimento da cultura e do conhecimento científico. Pretendia fazer da escola o fulcro da unidade moral da nação e do Estado. ${ }^{7}$ A Reforma Universitária deveria dar origem a uma instituição de ensino dinâmica, atualizada e geradora de novos saberes. Segundo a sua opinião: ${ }^{8}$

...todas as Sciencias se aperfeiçoão cada vez mais, e se enriquecem com descobrimentos novos, que logo devem incorporarse nos respetivos Cursos das Lições publicas; E por outra parte; que tem mostrado a experiência, que as Universidades nem tem infelizmente promovido estes conhecimentos, nem tem recebido com a promptidão os descobrimentos, que de novo se tem feito em todas estas Sciencias; porque sendo destinadas ao ensino publico se julgam limitadas a um Curso de Lições Positivas; e só trabalham, e se ocupam em conservar, e defender as que huma vez começaram a ensinar com grande prejuizo do Bem Comum, e do adiantamento das letras: Foi servido confederar as ditas Tres Profissoens de Naturalistas, Medicos, e Mathematicos em huma Congregação Geral, a qual tivesse por Instituto trabalbar no progresso, adiantamento, e perfeição

6 BRAGA, Theophilo - Dom Francisco de Lemos e a reforma da Universidade de Coimbra ; Relação geral do Estado da Universidade de Coimbra desde o principio da nova reforma até o mez de setembro de 1777 ... / Dom Francisco de Lemos. - Lisboa: Typographia da Academia Real das Sciencias, 1894.

7 ARAÚJO, Ana Cristina - Dirigismo Cultural e Formação das Elites no Pombalismo. In. O Marquês de Pombal e a Universidade. Coimbra : Imprensa da Universidade. (2000), p. 10.

8 LEMOS, ibidem. fl. 120 - 121. das mesmas Sciencias do modo que felismente se tem praticado, e pratica nas Academias mais Celebres da Europa; melhorando os Conhecimentos adquiridos, e adquirindo outros de novo, os quaes se fizessem logo passar aos Cursos respetivos das ditas Faculdades.

Na avaliação sobre o estado da UC, o Reitor Reformador exaltava a influência da Universidade no progresso científico, técnico e económico do país. O estudo das ciências naturais era indispensável para um melhor conhecimento das riquezas naturais, trazendo para a indústria novos recursos materiais, com o consequente desenvolvimento do comércio. Os objetivos da reforma foram enunciados em função de uma meta considerada prioritária e fundamental para o desenvolvimento da nação: o ensino experimental das ciências da natureza estimularia o desenvolvimento de novas artes, novas manufaturas, novas fábricas, e o aperfeiçoamento das existentes. Neste aspeto os resultados da reforma da Universidade tiveram repercussões assinaláveis no Brasil.

A 13 de maio de 1799 D. Francisco de Lemos foi pela segunda vez nomeado reitor da Universidade. Tomou posse no dia 16, cargo que ocupou até 27 de agosto de 1821, em que foi exonerado a seu pedido. O seu segundo mandato reitoral foi marcado pela invasão francesa. Enquanto a Universidade era encerrada e vários estudantes e professores se voluntariaram nos batalhões académicos que resistiram aos invasores, o Reitor assumiu uma atitude colaboracionista. Nesta época esteve ausente em França, tendo sido um dos membros escolhidos pelo general Junot, para fazer parte da deputação criada em 23 de fevereiro de 1808 com ordens para estar em Bayonne entre 1 e 10 de abril, encarregada de cumprimentar e prestar homenagem a Napoleão. ${ }^{9}$ Regressou sob proteção das tropas francesas, chegando a Portugal a 9 de novembro de $1810 .^{10}$ Foi eleito deputado às cortes gerais

9 Por ordem de Junot de 12 de maio de 1808, foi publicada em francês e português, na Gazeta de Liuboa e afixada por todo o Reino, uma carta escrita em 27 de abril de 1808, pela chamada Deputação portuguesa enviada a Napoleão Bonaparte, falando da situação de Portugal no interior do Império francês.

10 Hespanha, António Manuel - Sob o signo de Napoleão. A Súplica constitucional de 1808. Almanack Braziliense. $N^{\circ}$ 7. 2008. p. 80-101. 
e constituintes em 1821 pelo Rio de Janeiro, mas não chegou a tomar posse, e faleceu no ano seguinte.

\section{Monteiro da Rocha: Um projeto científico vindo do Brasil}

O mentor do programa de ensino das ciências físico-matemáticas do projeto pombalino de reforma da Universidade tinha vindo do Brasil. Com efeito, um dos grandes conselheiros da reforma pombalina foi José Monteiro da Rocha (1734-1819). Foi por intervenção do Reitor Reformador que o Marquês de Pombal teve conhecimento do seu mérito científico. Tendo-o chamado a Lisboa, encarregou-o da redação dos novos Estatutos da Universidade na parte das ciências físico-matemáticas. O percurso anterior de Monteiro da Rocha permanece incerto nalguns aspetos. Nascido em Canavezes, presumivelmente terá sido levado para o Brasil ainda jovem, onde ingressou na Companhia de Jesus em 1752. Aí terá feito os seus estudos no colégio dos jesuítas da Bahia. Depois da extinção da Ordem, continuou durante algum tempo na colónia, tendo sido encarregado da educação dos filhos do governador da Província. Em 1760 foi ordenado padre secular na Bahia. Depois do seu regresso a Portugal em 1766, fixou-se em Coimbra. Frequentou aí a Universidade entre 1766/7-1770, formando-se em Cânones. ${ }^{11}$

Por ocasião da passagem do cometa Halley, em 1758/1759, Monteiro da Rocha redigiu em Salvador, na Bahia, um manuscrito sobre a teoria dos cometas, que concluiu em março de 1760, quando ainda tinha apenas 25 anos de idade. Neste documento, intitulado Systema Physico-Matbematico dos Cometas coposto por occazião de hum que foi visto no ano de 1759 na cidade da Babya, Rocha analisava a sua natureza física e o modo de calcular as respetivas efemérides. ${ }^{12}$ Por razões que se desconhecem, o manuscrito escrito no Brasil

11 TEIXEIRA, António José - Apontamentos para a Biographia de José Monteiro da Rocha. O Instituto: Jornal Scientifico e Litterario. - Volume XXXVII (1889-1890), p. 65-98.

12 Apenas em 1799 José Monteiro da Rocha viria a publicar um estudo sobre a Determinação das Orbitas dos Cometas, nas Memórias da Academia Real das Sciencias de Lisboa (vol. 2, 1799, p. 402-479). manteve-se inédito na Biblioteca Pública de Évora ${ }^{13}$ até que o investigador brasileiro Carlos Ziller Camenietzki o encontrou e publicou em 2000. ${ }^{14}$ Ainda no Brasil, Monteiro da Rocha terá iniciado um estudo sobre uma solução matemática para a obtenção da longitude pelas distâncias lunares, o qual dedicou ao Senbor Conde de Oeiras, Ministro e Secretário dos Negocios do Reino. ${ }^{15}$

A formação obtida entre os mestres jesuítas no Brasil habilitou Monteiro da Rocha para o desempenho de um papel de relevo na Reforma Pombalina. Destacou-se na elaboração dos Estatutos da nova Faculdade de Matemática, nomeadamente do plano de estudos do Curso Mathematico. Porém a sua importância não se limitou ao período reformador. Tornar-se-ia uma das principais figuras da Faculdade de Matemática e da própria Universidade, tanto enquanto professor das cadeiras de Foronomia (1772-1783) e Astronomia (1783-1804) e Diretor do Observatório Astronómico (1795-1819), bem como vice-reitor (1786-1804). ${ }^{16} \mathrm{Um}$ dos mais importantes projetos em que se empenhou foi o da criação do Observatório Astronómico. A construção do edifício do Observatório previsto nos estatutos pombalinos passou por várias vicissitudes. Inicialmente foi delineado um imponente edifício, bem ajustado à grandiosidade do projeto pombalino para as ciências. Mas o plano inicial foi abandonado em setembro de 1775 , provavelmente, devido ao seu exagerado custo. Só em 1790 começou a ser erigido um edifício mais modesto no Paço das Escolas.

13 O Códice encontra-se no fundo Manizola n 506 na Biblioteca Pública de Évora.

14 CAMENIETZKI, C. Z. (Org.); PEDROSA, Fábio Mendonça (Org.) - Sistema físico-matemático dos cometas de José Monteiro da Rocha. Rio de Janeiro: MAST, 2000. CAMENIETZKI, Carlos Ziller; PEDROSA, Fábio Mendonça A Observação Cometária de José Monteiro da Rocha no Brasil Seiscentista. Anais do VII Seminário Nacional de História da Ciência e da Tecnologia. Editora da Universidade de São Paulo. 2001. p. 103-106.

15 PEREIRA, José Manuel Malhão - Um manuscrito de cerca de 1767, do P. José Monteiro da Rocha, S.J. com uma solução matemática para a obtenção da longitude pelas distâncias lunares. Cuadernos de Estudios Borjanos. L-LI, 2007-2008. p. 339-394.

16 FIGUEIREDO, Fernando de - O Programa curricular do Curso Mathematico delineado nos Estatutos Pombalinos (1772) e os primeiros livros adotados para o seu ensino: um estudo comparativo. Atas do Congresso Luso-Brasileiro de História das Ciências. Imprensa da Universidade de Coimbra. 2011. p. 184-198. 
Apenas ficou concluído em 1799, tendo existido até meados do século XX quando a Alta coimbrã foi completamente transformada - o edifício foi demolido. Para equipar o Observatório com os melhores instrumentos, Monteiro da Rocha encarregou-se de os encomendar aos mais conceituados fabricantes ingleses através de João Jacinto de Magalhães, na época a viver em Londres. ${ }^{17}$

\section{Um brasileiro na origem do Laboratório Chimico}

Com a Reforma Pombalina da Universidade a Química emergiu em Portugal com assinalável atualidade. O italiano Domenico Agostino Vandelli (Pádua, 1735 - Lisboa, 1816) foi contratado pelo Marquês de Pombal para ensinar Química e História Natural, sendo vários os brasileiros que sob a sua orientação obtiveram formação científica e técnica. ${ }^{18}$ Os Estatutos Pombalinos estabeleciam com clareza o objeto da Filosofia Química, definindo as razões da inserção desta disciplina no Curso Filosófico e determinando a natureza experimental do ensino pretendido. ${ }^{19}$ Para que as experiências relativas ao curso das lições fossem realizadas com bom proveito dos estudantes foi criado um moderno e amplo laboratório. Foi concebido para que aí se pudessem fazer as preparações químicas destinadas ao uso das artes em geral e da medicina em particular. Os estudantes que se destinavam a frequentar o Curso Médico deveriam ter uma preparação prévia em Química. ${ }^{20}$ Esta ciência

17 Figueiredo, Fernando José Bandeira de - José Monteiro da Rocha e a atividade científica da "Faculdade de Mathematica" e do "Real Observatório da Universidade de Coimbra": 1772-1820. Tese de doutoramento. Coimbra: [s.n.], 2011 .

18 O seu filho Alexandre Antonio Vandelli, nasceu em Coimbra a 27 de junho de 1784 e viria a naturalizar-se brasileiro. MARQUES, Adílio Jorge; FILGUEIRAS Carlos A. L. - O químico e naturalista luso-brasileiro Alexandre Antonio Vandelli. Química Nova. vol. 32 no.9. 2009. p. 2492-2500.

19 FERRAZ, Márcia H. M. - As ciências em Portugal e no Brasil (1772-1822): o texto conflituoso da química. São Paulo: Educ/ Fapesp, 1997.

20 FILGUEIRAS, Carlos A. L.. A influência da Química nos saberes médicos acadêmicos e práticos do século XVIII em Portugal e no Brasil. Química Nova [online]. 1999, vol.22, n.4 [cited 2011-12-14], pp. 614-621.

Disponível em: http://www.scielo.br/scielo.php?script=sci_arttext\&pid=S0100 $40421999000400022 \& \operatorname{lng}=\mathrm{en} \& \mathrm{nrm}=$ iso. foi instituída como disciplina autónoma no Curso Filosófico, com o objetivo de indagar as propriedades particulares dos corpos: analisando os seus princípios, examinando os elementos de que se compõem e descobrindo os efeitos e propriedades relativas que resultam da mistura e aplicação íntima de uns aos outros. ${ }^{21}$

$\mathrm{Na}$ origem do Laboratório Chimico encontramos um brasileiro: José Francisco Leal - natural do Rio de Janeiro (1744), morreu em Coimbra (1786). Num ofício do Marquês de Pombal para o Reitor da Universidade de 12 de fevereiro de 1773 pode ler-se:

Fica porem ainda aqui a planta do Laboratorio Chymico, que foi necessário formar-se pelo modelo, que o Dr. José Francisco Leal trouxe por minha ordem da côrte de Vienna de Austria, havendo eu conhecido que o paiz de Alemanha he aquele em que a referida arte tem chegado ao gráo de mayor perfeição.

A determinação de Pombal para que o projeto apresentado por Francisco Leal não ficasse sob qualquer pretexto comprometido ficou bem expresso nas palavras do ministro: ${ }^{22}$

Esta planta chegará porém brevemente à presença de V. S. ${ }^{a}$ com o tenente-coronel Guilherme Elsden, de cuja notoria desteridade se ajudará V. S. ${ }^{a}$ tão utilmente, como já lhe mostrou a experiência do serviço que ahi fez o referido oficial. Não deve V. S. ${ }^{a}$ coangustar-se pela falta de meios necessários para se effectuarem as referidas obras. A indispensável necessidade d'ellas deve prevalecer a todo reparo dos antigos zelos.

Coimbra passou a ter um moderno laboratório para estudos de processos químicos e metalúrgicos, que é contemporâneo do que

21 COSTA, A. M. Amorim da-De Stahl a Lavoisier em Portugal Setecentista. Química, Boletim da Sociedade Portuguesa de Química n 32/33 (Série II), (1988). p. 8-10.

22 Carta de 12 de fevereiro de 1773 do Marquês de Pombal ao reitor-reformador in Coleção Geral das Ordens, fl. 92. 
é considerado o grande fundador da Química: o francês Antoine Laurent de Lavoisier (1743-1794). O projeto foi concretizado e na Relação Geral Sobre o Estado da Universidade Francisco de Lemos afirmava: $:^{23}$

Para fundar este Estabelecimento aplicou o Marquez Visitador a parte septemtrional do Collegio, que comprehendia o refeitorio, e as mais officinas adjacentes. E não podendo também servir todos estes edifícios para o Laboratorio, foi preciso demolir tudo e edificar de novo o Edifício... ${ }^{24}$

Acha-se feito o mesmo Edifício, e só necessita de alguns ornatos, e perfeiçoens, que não impedem o uso, que se faz delle, para as Demonstraçoens, e Processo Chimicos.

Criado o Laboratório Chimico, a Química em Coimbra teve um desenvolvimento significativo, acompanhando as evoluções mais recentes observadas nos principais centros europeus. ${ }^{25}$ Este processo teve um contributo assinalável do brasileiro Vicente Coelho de Seabra Silva Telles. ${ }^{26}$ Nascido em 1764 em Congonhas do Campo, no Estado de Minas Gerais, veio para Coimbra em 1783. Em 1786 terminara os estudos preparatórios de Filosofia e Matemática e concluiu o Curso de Medicina em 1791. No entanto a vocação de Seabra era a Química. No mesmo ano em que completou os seus estudos médicos foi nomeado demonstrador da cadeira de Química e Metalurgia. Em 1788/1789, com apenas 24 anos e quando ainda era estudante de Medicina, publicou o livro Elementos de Química com uma dedicatória à Sociedade Litteraria do Rio de Janeiro para o uso do seu curso de Química. ${ }^{27}$ Dividiu o compêndio em duas partes:

\section{LEMOS, ibidem, fl. 147}

24 Não terá sido demolido todo o edifício do antigo refeitório dos jesuítas. Atualmente podemos ver no Museu da Ciência da Universidade de Coimbra vestígios bem assinaláveis do que teria sido aquele imponente refeitório. Alguns anexos situados na ala norte do edifício principal, foram efetivamente demolidos.

25 COSTA, A. M. Amorim da - A Universidade de Coimbra na Vanguarda da Química do Oxigénio. Publicações do II Centenário da Academia das Ciências de Lisboa, vol. 2. 1986. p. 403-416,

26 FILGUEIRAS, Carlos A. L. - Vicente Telles, o primeiro químico brasileiro. Química Nova. n. 8. 1985. p. 263-270.

27 TELLES, Vicente Coelho de Seabra Silva - Elementos de chimica offerecidos a Sociedade Litteraria do Rio de Janeiro para o uso do seu curso de chimica. a primeira publicada um ano antes de Lavoisier dar à estampa o seu famosíssimo Traité Élémentaire de Chimie (1789) e a segunda parte editada um ano após a publicação deste tratado. Nesta obra Seabra já defendia as principais ideias da Química de Lavoisier, em oposição às anteriores ideias do flogisto, o que lhe valeu algumas críticas e contestação por parte dos defensores das teorias químicas então mais difundidas. Em 1801 publicou uma tradução adaptada para a língua portuguesa da nomenclatura química de Lavoisier com o título: Nomenclatura Cbimica Portugueza, Franceza e Latina: à que se ajjunta o systema de characteres chimicos adaptados a esta nomenclatura por Haffenfratz e Adet. ${ }^{28}$ Infelizmente faleceu pouco antes de fazer 40 anos, ficando por se concretizar a sua promissora carreira académica e científica. Morreu em Coimbra em 1804.

\section{Brasileiros na Faculdade de Medicina}

Na Faculdade de Medicina despontaram vários nomes brasileiros que se destacaram no desenvolvimento das ciências da saúde no Reino e no Brasil. ${ }^{29}$ Após a colaboração para a criação do Laboratório Cbimico, José Francisco Leal viria a ser nomeado no dia 3 de outubro de 1772 para reger cadeiras da Faculdade de Medicina. No dia 9 desse mês foi-lhe conferido o grau de Doutor, sendo nomeado como Lente de Pbisiologia, Matéria Médica e Instituições Médico-cirúgicas. Foi autor das Instituções ou Elementos da Pharmacia, extrabidos dos de Baumé, e reduzidos a um novo methodo, obra publicada postumamente em 1792 por Manuel Joaquim Henriques de Paiva (Castelo Branco, 1756 - Bahia, 1829). ${ }^{30}$ Além

Coimbra: na Real Officina da Universidade, 1788-1790.

28 Publicado em Lisboa, na Typographia chalcographica, typoplastica, e litteraria do Arco do Cego, Lisboa. 1801.

29 PITA, João Rui - Medicina, cirurgia e arte farmacêutica na reforma pombalina da Universidade de Coimbra In: ARAÙJO, Ana Cristina (coord.). - O marquês de Pombal e a universidade de Coimbra. Coimbra: Imprensa da Universidade, 2000, p. 129-162.

30 Henriques de Paiva viveu no Brasil a partir dos sete anos de idade. Em 1772 veio para Coimbra para tirar o Curso de Medicina, frequentando antes o Curso de Filosofia, obtendo o grau de bacharel em 1775. O seu envolvimento com os franceses, durante a ocupação, aliadas às suas ideias liberais e maçónicas fizeram com que se 
da prática profissional, nesta obra Francisco Leal tratou com mestria os aspetos relacionados com o ensino da Farmácia, dando à Química um papel de relevo. Este livro pode ser considerado um verdadeiro tratado de Farmácia prática. A preocupação do autor consistia em descrever as formas farmacêuticas e as técnicas laboratoriais na respetiva preparação.

Para a concretização do projeto de Reforma da Faculdade de Medicina, o Marquês de Pombal pôde contar com a colaboração de outro brasileiro: José Correia Picanço (primeiro Barão de Goiana). Nascido no Recife em 10 de novembro de 1745, viria a falecer no Rio de Janeiro em 1824. Era formado em Medicina pela Faculdade de Montpellier. Identificado com o projeto pombalino de renovação do Curso Médico, substituiu o italiano Luigi Cichi que fora afastado por desleixo. Correia Picanço foi nomeado opositor na Faculdade de Medicina em 1772, onde foi jubilado em 1790 como lente de Anatomia, sendo considerado o grande reformador do seu ensino em Portugal. Retornou ao Brasil com D. João VI em 1807, obtendo autorização régia para criar o primeiro curso de medicina do Brasil, na cidade de Salvador. ${ }^{31}$ Em 18 de fevereiro de 1808 foi criada a Escola de Cirurgia da Bahia, segundo um plano inspirado nos preceitos definidos nos estatutos pombalinos da UC. ${ }^{32}$ Foi instalada no antigo Hospital Real Militar da Cidade do

retirasse para o Brasil, em 1809. Continuou os seus trabalhos científicos na Bahia. Em 1818, por ocasião da coroação de João VI, Manuel Joaquim foi reabilitado, recebendo honras, e prerrogativas que gozara e perdera. Contudo, não mais voltou para Portugal. Veio a naturalizar-se brasileiro, após a independência do Brasil em 1822. FILGUEIRAS, Carlos A. L. - As Vicissitudes da Ciência Periférica: A Vida e a Obra de Manoel Joaquim Henriques de Paiva. Química Nova. 14(2). 1991. p. 133-141. PITA, Rui João - Manuel Joaquim Henriques de Paiva: Um luso-brasileiro divulgador de ciência. O caso particular da vacinação contra a varíola. Mneme: Revista de Humanidades. Publicação do Departamento de História e Geografia da Universidade Federal do Rio Grande do Norte. Vol. 10, n. 26. 2009. p. 91-102. PINTO, Sandrine Martins; PITA, João Rui; PEREIRA, Ana Leonor - O contributo do Luso-Brasileiro Manuel Joaquim Henriques de Paiva (1752-1829) na divulgação da vacina contra a varíola em Portugal. Atas do Congresso Luso-Brasileiro de História das Ciências. Imprensa da Universidade de Coimbra. 2011. p. 633-644.

31 Correia Picanço foi o médico que acompanhou o parto da Imperatriz Maria Leopoldina de Áustria, do qual nasceu D. Maria da Glória, a 4 de abril de 1819, no Rio de Janeiro, futura rainha de Portugal (Maria II de Portugal).

32 Dicionário Histórico-Biográfico das Ciências da Saúde no Brasil (1832-1930). Casa de Oswaldo Cruz / Fiocruz - (http://www.dichistoriasaude.coc.fiocruz.br). Consultado em 15/11/2011.
Salvador, que ocupava o prédio do antigo Colégio dos Meninos da Companhia de Jesus, fundado em 1551. Dois meses depois, Correia Picanço fundou a Escola Anatómica, Cirúrgica e Médica do Rio de Janeiro. Em 2 de março de 1812 foi criada a Junta de Direção Médico-Cirúrgica e Administrativa do Hospital Real Militar e Ultramar do Rio de Janeiro, à qual caberia a inspeção das aulas ministradas no Hospital, obedecendo os estatutos da Faculdade de Medicina de Coimbra. Em 1816 a Escola de Cirurgia da Bahia, sofreu a sua primeira reforma, adotando o plano semelhante ao aprovado em 1813 pela Escola do Rio de Janeiro. Passou a ser designada Academia Médico-Cirúrgica da Bahia e posteriormente, em 1832 deu origem à Faculdade de Medicina da Bahia. ${ }^{33} \mathrm{O}$ plano de reforma destas duas escolas foi da autoria de outro médico brasileiro formado em Coimbra e discípulo de Francisco Leal e Correia Picanço: Manoel Luiz Alvares de Carvalho (Bahia, 1751 - Rio de Janeiro, 1825) que se formou em Medicina em 13 de julho de $1782 .{ }^{34}$

Com a Viradeira, ocorrida após a destituição do Marquês de Pombal, os livros proibidos proliferavam em Coimbra, e a simples posse era sancionada pelo Santo Ofício. Alguns estudantes foram alvo de processos persecutórios, entre os quais alguns brasileiros que estavam mais vulneráveis que os outros, longe da terra natal e privados do apoio dos parentes chegados onde pudessem procurar alguma proteção. Desprotegidos e vítimas de delação foram presos três estudantes oriundos do Brasil: António Pereira de Sousa Caldas (1762-1814), o Caldinhas, que em 1778, tinha iniciado o curso de Matemática, cuja frequência no primeiro ano se exigia para os candidatos ao curso de Cânones; António de Morais e Silva (1755-1824) estudante de Cânones; e Francisco de Mello Franco (1757-1823), natural de Paracatú, Minas Gerais. ${ }^{35}$ Mello Franco foi um dos médicos que se formou no contexto de renovação dos

33 SANTOS, Roberto Figueira - No bicentenário da criação da "Escola de Cirurgia” da Bahia. Gazeta Medica da Bahia. 77 (2). 2007. p. 89-92.

34 BRENES, Anayansi Correa - História da parturição no Brasil, século XIX. Cadernos de Saúde Pública [online]. 1991, vol.7, n.2, p. 135-149.

35 Villalta, Luiz Carlos - Reformismo Ilustrado, censura e práticas de leitura: usos do livro na América Portuguesa. Tese de Doutoramento. Faculdade de Filosofia, Letras e Ciências Humanas. Universidade de São Paulo. 1999. 
estudos médicos em Portugal e cuja obra tem merecido poucos estudos na historiografia brasileira. ${ }^{36}$ Ainda com a idade de 21 anos, num ambiente universitário em grande convulsão, Mello Franco envolveu-se em 1778 na contestação à autoridade e tradições universitárias. Em 1781, em consequência do seu entusiasmo pelos enciclopedistas, foi alvo de um processo movido pela Inquisição. Daqui resultou um auto-da-fé celebrado em Coimbra em 26 de agosto, com a acusação de herege naturalista e de negar o sacramento do matrimónio. Após quatro anos de prisão, concluiu o Curso de Medicina em 1786. Reagindo à lamentável situação de que fora vítima, fez circular em 1785 um poema anónimo intitulado O Reino da Estupidez, ridicularizando a UC e o seu Reitor. ${ }^{37}$ Para a sua divulgação contou com a ajuda de José Bonifácio de Andrada e Silva (1763-1838), que fez algumas cópias do poema. O texto causador de grande polémica em Coimbra, tornado público sob o pseudónimo de Fabrício Cláudio Lucrécio, foi objeto de várias publicações em Portugal (Lisboa, 1822, 1823, 1833 e Barcelos 1868), França (Paris, 1818, 1821, 1824) e Alemanha (Hamburgo 1820). Sobre este episódio, Teófilo Braga viria a escrever o seguinte: ${ }^{38}$

Atribuiu-se ao Dr. António Ribeiro dos Santos, homem grave, erudito e privado de todo o espírito irónico; atribuiu-se ao jovem poeta brasileiro António Pereira de Sousa Caldas, que saíra da Inquisição de Coimbra, e se achava em 1784 em Paris; também se chegou a atribuir a Ricardo Raimundo Nogueira. Estavam todos inocentes desse louvável pecado. Ninguém imaginava que o Reino da Estupidez era uma sublime vingança do estudante de medicina Francisco de Mello Franco, que jazera nos cárceres da Inquisição de Coimbra por o acusarem de Enciclopedista.

36 ABREU, Jean Luiz Neves - A educação física e moral dos corpos: Francisco de Mello Franco e a medicina luso-brasileira em fins do século XVIII. Estudos Ibero-Americanos. PUCRS, v. XXXII, n. 2, 2006. p. 65-84.

37 FRANCO, Francisco de Mello - O reino da estupidez: poema. Paris: A. Bobée, 1818; Hambourg: [s.n.], 1820; Lisboa: Imp. J. Nunes \& Filhos, 1833.

38 BRAGA, Teófilo - História da Universidade de Coimbra. Lisboa: Por ordem e na Typographia da Academia Real das Sciencias, vol. III, 1898. p. 675 a 697.
Em 1787, um ano após a conclusão do curso de Medicina, Mello Franco foi admitido na Real Academia das Ciências de Lisboa, tendo chegado a vice-presidente. Em 8 de abril de 1812, um dos académicos, o médico Bernardino António Gomes (1768 - 1823) propôs "hum Arbitrio para promover a Vacinação a benefício da Saude Publica", que esteve na origem da Instituição Vacínica, cujo regulamento foi aprovado em 14 de outubro de 1812. O grupo de médicos que esteve na origem da Instituição Vacínica era constituído por Bernardino António Gomes, Francisco de Mello Franco (brasileiro), Francisco Soares Franco e José Maria da Cunha Pessoa, a que se juntariam logo de seguida, José Maria Soares, José Pinheiro de Freitas, José Feliciano de Castilho e Francisco Elias Rodrigues da Silveira (natural do Brasil). ${ }^{39}$ Mello Franco e Bernardino António Gomes foram encarregados por D. João VI, em 1817, para se deslocarem a Livorno a fim de acompanharem a princesa D. Maria Leopoldina até ao Rio de Janeiro. No domínio da saúde pública, Mello Franco realizou um estudo sobre as febres com observações analíticas acerca da topografia, clima e demais particularidades, que influem no caráter das febres do Rio de Janeiro. ${ }^{40}$ No Brasil, Franco notabilizou-se como médico pediatra e é considerado o primeiro puericultor brasileiro ${ }^{41}$, tendo-se dedicado também à dietética. ${ }^{42}$ No final da sua vida, sentindo-se doente terá querido voltar para Portugal, mas terá falecido perto de Ubatuba, durante uma viagem marítima de Santos para o Rio de Janeiro, embora as condições da sua morte sejam objeto de alguma divergência.

39 SILVA, José Alberto - A Instituição Vacínica da Real Academia das Ciências de Lisboa: Uma rede contra a varíola. Atas do Congresso Luso-Brasileiro de História das Ciências. Imprensa da Universidade de Coimbra. 2011. p. 683-701. 40 FRANCO, Francisco de Mello - Ensaio sobre as febres com observações analíticas acerca da topografia, clima e demais particularidades, que influem no caráter das febres do Rio de Janeiro. Lisboa. Tipografia da Academia Real de Ciências de Lisboa. 1829.

41 FERREIRA, António Gomes - A compreensão médica portuguesa sobre a concepção da criança no século XVIII. Educar, Curitiba, Editora UFPR. 2005. n. 25, p. 17-38.

42 BIZZO, Maria Leticia Galluzzi - "Tudo o que não é vivificado, é expulso deste admirável laboratório vital”: Francisco de Mello Franco (1757-1822) e a dietética iluminista. Atas do Congresso Luso-Brasileiro de História das Ciências. Imprensa da Universidade de Coimbra. 2011. p. 594-613. 
Um dos primeiros estudantes brasileiros formados pela UC no contexto dos novos planos de estudos foi Francisco José de Lacerda e Almeida (São Paulo, 1750 - África, 1798). Em 1772 iniciou os cursos de Matemática e de Filosofia. Concluídos os seus estudos serviu a Coroa como Matemático e Cartógrafo em expedições no Brasil e no continente africano. Em 1777, aos vinte e sete anos, recebeu o grau de doutor em Matemática. Regressando ao Brasil, nos anos de 1780 a $1790 \mathrm{fez}$ parte de uma comissão para a determinação dos limites das suas fronteiras, percorrendo as capitanias do Pará, Rio Negro, Mato-Grosso ${ }^{43}$, Cuiabá, e S. Paulo, retornando a Portugal em 1791. ${ }^{44}$ Em 1798 participou num grande projeto de travessia da costa oriental de África à contracosta de Angola, tendo falecido em outubro desse ano no decurso desta expedição ao chegar ao Cazembe - a Noroeste do Niassa, que ficou narrada no manuscrito intitulado Instruções e Diário de Viagem que o Governador Francisco José de Lacerda e Almeida Escreveu sobre Sua Viagem para o Centro da África, Indo do Rio do Sena, no Ano de 1798.45 No interior africano Lacerda e Almeida tinha por objetivo descobrir uma rede fluvial que permitisse a ligação continental entre as costas oriental e ocidental, ligando Moçambique a Angola. ${ }^{46}$ Realizou observações astronómicas

43 FERREIRA, Mário Clemente - Cartografar os Sertão: A representação de Mato Grosso no século XVIII. II Simpósio Luso-Brasileiro de Cartografia Histórica, Lisboa. 2007. Disponível em http://www.igeo.pt/servicos/DPCA/ PDF/022_MarioClementeFerreira.pdf. Consultado em 9/12/2011.

44 ALMEIDA, Francisco José de Lacerda - Diario da viagem do Dr. Francisco José de Lacerda e Almeida pelas capitanias do Pará, Rio Negro, Matto-Grosso, Cuyabá, e S. Paulo, nos annos de 1780 a 1790. São Paulo: Typ. de Costa Silveira. 1841.

Disponível em http://www.brasiliana.usp.br/bbd/handle/1918/00021500\#page/5/ mode/lup. Consultado em 5 de dezembro de 2011.

45 Disponível em http://www.wdl.org/pt/item/234/. Consultado em 27/12/2011. O Diário de viagem foi publicado nos Annaes Marítimos e Coloniaes, série n. ${ }^{4}$, p. 286-300, 303-314, 334-343, 377-381, 397-408, e na Série n. ${ }^{\circ}$ 5, p. 29-26, 63-77, 108-120. Em 1889 a Imprensa Nacional publicou o diário com o título "Diário da viagem de Mossambique para os Rios da Sena feita pelo governador dos mesmos rios o D.or Francisco José de Lacerda e Almeida".

46 O relatório da viagem foi publicado em Londres pela Royal Geographical Society. The lands of Cazembe - Lacerda's journey to Cazembe in 1798 translated feitas na África Central, incluindo cuidadosas determinações de longitude pela ocultação dos satélites de Júpiter.

Nascido em 1750, na comarca de Mariana, Minas Gerais, Antonio Pires da Silva Pontes Leme iniciou os seus estudos em Coimbra por volta de 1772. Formou-se em Matemática e Filosofia e obteve o grau de doutor em Matemática no ano de 1778. Nos dez anos seguintes, a sua atividade de matemático e astrónomo ao serviço do Reino esteve associada à de Lacerda e Almeida. ${ }^{47}$ Foram ambos nomeados matemáticos astrónomos da Terceira Partida de Demarcação de Limites do Brasil, organizada em consequência do tratado de Santo Ildefonso, assinado no dia 1 de outubro de 1777 entre a rainha de Portugal, D. Maria I, e o rei de Espanha, Carlos III. Os dois matemáticos compunham o corpo expedicionário que partiu do porto de Lisboa em janeiro de 1780, em direção ao Pará. ${ }^{48}$ Tendo percorrido os principais rios e explorado os limites ocidentais da Amazónia, estabeleceram as novas coordenadas geográficas que corrigiam e refaziam os mapas existentes. Silva Pontes partiu depois em expedição para o Mato Grosso. ${ }^{49}$ Tendo regressado a Portugal, continuaria a trabalhar com Lacerda e Almeida como professores na Academia de Marinha. Em 1801 regressou ao Brasil, assumindo o governo do Estado do Espírito Santo.

and annotated by R. F. Burton. Also Journey of the pombeiros, P. J. Batista and Amaro Jose', across Africa from Angola to Tette on the Zambeze, translated by B. A. Beadle. And a Re'sume' of the journey of MM. Monteiro and Gamitto, by C. T. Beke. Published in 1873 by John Murray in London. Disponível em http://openlibrary.org/books/OL6960360M/The_lands_of_Cazembe. Consultado em 5 de dezembro de 2011.

47 CRUZ, Ana Lúcia Rocha Barbalho da - As Viagens são os viajantes: Dimensões identitárias dos viajantes naturalistas brasileiros do século XVIII. História: Questões \& Debates. Editora UFRP. Curitiba. N. 36. 2002. p. 61-98.

48 PEIXOTO, Renato Amado - Impernitentes, desinteressados ou sem escolha: os Demarcadores e as demarcações portuguesas no norte do Brasil durante a década de 1780. Anais o II Encontro Internacional de História Colonial. Mneme - Revista de Humanidades. UFRN. Caicó (RN), v. 9. n. 24. 2008. Disponível em www.cerescaico.ufrn.br/mneme/anais. Consultado em 10/11/2011.

49 MARTINS, Francisco José Corrêa - Compilar para conhecer: alguns mapas do território colonial brasileiro da mapoteca do Arquivo Histórico do Exército. III Simpósio Luso-Brasileiro de Cartografia Histórica. Ouro Preto. Minas Gerais. 2009. Disponível em http://www.ufmg.br/rededemuseus/crch/ martins_compilar-para-conhecer-alguns-mapas-do-territorio-colonial-brasileiro. pdf. Consultado em 5/12/2011. 
No Rio de Janeiro e São Paulo foram realizados importantes estudos de meteorologia e astronomia por cientistas formados segundo os planos de estudos das novas Faculdades. Bento Sanches d'Orta (Coimbra, 1739 - São Paulo 1794) frequentou os Cursos de Filosofia e Matemática. Na sequência do Tratado de Santo Ildefonso, Sanches d'Orta e Francisco de Oliveira Barbosa (?-?) foram enviados para o Brasil, sob a supervisão do lente da Faculdade de Matemática, o italiano Miguel António Ciera, onde empreenderam uma missão para a demarcação dos limites na região Sul do Brasil, tendo chegado ao Rio de Janeiro em 1781. Ciera já tinha iniciado este projeto de demarcação da América Meridional numa expedição realizada entre 1752/56 com o propósito de elaborar o Mappa Geograficum quo Flumen Argentum, Paranà et Paraguay,... oferecido ao Rei D. José I em $1758 .{ }^{50}$ Durante sete anos os seus discípulos realizaram no Rio de Janeiro observações meteorológicas, astronómicas e magnéticas. Também determinaram a sua latitude e a longitude a partir das observações dos satélites de Júpiter. Após estes estudos seguiram para São Paulo, em 1788, dos quais resultaram as publicações dos relatórios intitulados Observaçõed Astronómicas e Meteorológicas Feitas na Cidade de São Paulo, América Meridional, no Período de 1788 a 1789, e do Diário Physico-Meteorológico de outubro, novembro e dezembro de 1788 da Cidade de São Paulo. Alguns instrumentos utilizados na definição das fronteiras brasileiras foram encomendados pela coroa portuguesa e enviados de Inglaterra por João Jacinto Magalhães. ${ }^{51}$ Os registos efetuados no Rio de Janeiro e São Paulo podem ser considerados o início da Meteorologia no Brasil. Sanches d'Orta também aplicou os conhecimentos químicos adquiridos em Coimbra, com o seu mestre Vandelli, e durante nove anos analisou as virtudes das águas de ribeiros e fontes, sob as ordens do Governador e Capitão de São Paulo, Bernardo José Maria Lorena e Silveira. Outro empreendimento em que d'Orta esteve envolvido

50 COSTA, Maria de Fátima - Miguel Ciera: um demarcador de limites no interior sul-americano (1750-1760). Anais do Museu Paulista, N. Sér. v. 17. n. 2. 2009. p. 189-214.

51 MALAQUIAS, Maria Isabel - João Jacinto de Magalhães e a definição das fronteiras brasileiras. Revista da Sociedade Brasileira de História da Ciência. $\mathrm{N}^{\circ}$ 1. Vol 2. 2003. P. 94-102. foi a elaboração de um relatório de observações astronómicas para facilitar a entrada de navios na Baía de Santos. ${ }^{52}$

\section{Os naturalistas e as viagens Philosophicas}

A História Natural terá sido a área científica do projeto pombalino da reforma universitária com mais auspiciosos resultados, impulsionando um melhor conhecimento dos recursos naturais do reino e império colonial português. ${ }^{53} \mathrm{O}$ apoio do Estado garantiu que os jovens naturalistas formados por Vandelli servissem a Corte através das viagens philosophicas que trouxeram à luz novos conhecimentos científicos e se procedesse à prospeção dos recursos naturais dos seus domínios territoriais. ${ }^{54}$ Entre os expedicionários formados na Faculdade de Filosofia assumiram particular destaque alguns oriundos do Brasil. O mais notável foi Alexandre Rodrigues Ferreira (Bahia, 27 de abril de 1755 Lisboa 1815). ${ }^{55}$ Frequentou o Curso Jurídico em 1770 e em 1772 matriculou-se no curso de Filosofia. Em 10 de janeiro de 1779 tomou o grau de doutor e começou a trabalhar no Real Museu de História Natural d’Ajuda. Aos 22 anos, Rodrigues Ferreira foi o nomeado por D. Maria I como primeiro naturalista português encarregado da expedição científica denominada Viagem Filosófica

52 NADER, Rundsthen Vasques - Bento Sanches Dorta: Um astrónomo da Corte nos trópicos. In Scientiarium História II. Encontro Luso-Brasileiro de História da Ciência. Universidade Federal do Rio de Janeiro. 2009. p. 529-533.

53 DOMINGUES, Ângela - Para um melhor conhecimento dos domínios coloniais: a constituição de redes de informação no Império português em finais do Setecentos. História, Ciências, Saúde - Manguinhos. [online]. 2001, vol.8, suppl., p. 823-838.

54 PATACA, Ermelinda Moutinho; PINHEIRO, Rachel - Instruções de viagem para a investigação científica do território brasileiro. Revista da Sociedade Brasileira de História da Ciência. Rio de Janeiro, v. 3, n. 1, 2005. p. 58-79.

55 RAMinelli, Ronald - Do conhecimento físico e moral dos povos: iconografia e taxionomia na Viagem Filosófica de Alexandre Rodrigues Ferreira. História, Ciências, Saúde - Manguinhos. [online]. 2001, vol.8, suppl., pp. 969 992. VERRAN, Rossana Samarani - Inventário científico do Brasil no século XVIII: A contribuição de Alexandre Rodrigues Ferreira para o conhecimento da Natureza e dos índios. Tese de Doutorado. Faculdade de Ciências Humanas da Pontifícia Universidade do Rio Grande do Sul. Porto Alegre. 2006. 
pelas Capitanias do Grão-Pará, Rio Negro, Mato Grosso ${ }^{56}$ e Cuiabá. ${ }^{57}$ Começada a ser planeada em 1778, a expedição teve início a 31 de agosto de 1783, com a missão complementar a Comissão de Demarcação de Limites entre as fronteiras dos domínios de Portugal na América, prevista pelo Tratado de Santo Ildefonso. Além disso, pretendia-se um melhor conhecimento do centro-norte da colónia brasileira, até então praticamente inexplorado, a fim de lá implementar medidas para o seu desenvolvimento. ${ }^{58}$

Outros brasileiros, alunos de Vandelli, trabalharam sob a direção do antigo mestre no Real Museu de História Natural e Jardim Botânico da Ajuda, em Lisboa, após a conclusão dos estudos Philosophicos em Coimbra. ${ }^{59}$ Durante a fase preparatória das viagens philosophicas eram elaboradas instruções de viagem, compostas por Vandelli com a participação dos seus discípulos. ${ }^{60}$ Após a experiência adquirida em viagens de exploração de recursos naturais no reino, foram incumbidos de missões no Brasil e nas colónias africanas ${ }^{61}$, procurando assim cobrir todo o vasto império colonial português. ${ }^{62}$

56 COSTA, Maria de Fátima - Alexandre Rodrigues Ferreira e a capitania de Mato Grosso: imagens do interior. História, Ciências, Saúde - Manguinhos. Rio de Janeiro. [online]. 2001, vol.8, suppl., pp. 993-1014.

57 CARVAlHO, José Candido de Melo - Viagem Filosófica pelas capitanias do Grão Pará, Rio Negro, Mato Grosso e Cuiabá (1783-1793). Ed. Conselho Nacional de Desenvolvimento Científico e Tecnológico - Museu Paraense Emílio Goeldi. Ministério da Educação e Cultura. Secretaria de Ensino Superior. Universidade Federal do Pará. 1983.

58 AREIA, Manuel Rodrigues Laranjeira; MIRANDA, Maria Arminda; MARTINS, Maria do Rosário - Da Universidade de Coimbra ao Brasil: É muito o que nos une. Atas do Congresso Luso-Brasileiro de História das Ciências. Imprensa da Universidade de Coimbra. 2011. p. 171-183.

59 CRUZ, Ana Lúcia Rocha Barbalho da - As Viagens são os viajantes: Dimensões identitárias dos viajantes naturalistas brasileiros do século XVIII. História: Questões \& Debates. Editora UFRP. Curitiba. N. 36. 2002. p. 61-98. 60 PATACA, Ermelinda Moutinho - Coletar, preparar, remeter, transportar práticas de História Natural nas viagens filosóficas portuguesas (1777-1808). Anais do XXVI Simpósio Nacional de História - ANPUH. São Paulo, julho 2011. Disponível em http://www.snh2011.anpuh.org/resources/anais/14/1300882030_ ARQUIVO_ermelindaanpuh2011.pdf. Consultado em 6/01/2012.

61 PEREIRA, Magnus Roberto de Mello - Brasileiros a serviço do Império; a África vista por naturais do Brasil, no século XVIII. Revista Portuguesa de História. Coimbra. v. 33. 1999. p. 153-190.

62 PATACA, Ermelinda Moutinho - Terra, água e ar nas viagens científicas portuguesas (1755-1808). Tese (doutorado). Universidade Estadual de Campinas.
- Joaquim José da Silva (nasceu no Rio de Janeiro). Foi enviado para Angola. ${ }^{63}$

- João da Silva Feijó (natural do Rio de Janeiro). Foi para a Ilha de Cabo Verde, onde chegou em junho de 1783. Em 1822 regressou ao Brasil onde viria a ser professor de História Natural, Zoológica e Botânica da Academia Militar do Rio de Janeiro.

- Manuel Galvão da Silva (nasceu na Bahia). Esteve em Goa e foi nomeado secretário de governo em Moçambique.

- Manuel Arruda Câmara (natural de Pombal, Paraíba). Depois de frequentar a Faculdade de Filosofia na $U^{64}$ foi estudar Medicina na Universidade de Montpellier, em França. Foi eleito membro da Academia das Ciências de Lisboa em 15 de maio de 1793. Regressado ao Brasil, entre 1794 e 1799 fez expedições mineralógicas e botânicas entre Pernambuco e Piauí, Paraíba e o Ceará e ao longo do rio São Francisco. ${ }^{65}$

- Joaquim Velloso de Miranda (nasceu no Inficionado - hoje Santa Rita Durão, Mariana. Era sobrinho de Frei José Santa Rita Durão). Após a conclusão do Curso de Filosofia foi lente substituto de História Natural e Química. Em 1779 regressou a Minas Gerais,

Instituto de Geociencias. Campinas, SP. 2006. PATACA, Ermelinda Moutinho. A confeção de desenhos de peixes oceânicos das "Viagens philosophicas" (1783) ao Pará e à Angola. História, Ciências, Saúde - Manguinhos. Rio de Janeiro. 2003, vol.10, n.3, pp. 979-991. PATACA, Ermelinda Moutinho - Viagens Científicas no Império Português (1755-1808). I Simpósio de Pesquisa em Ensino e História de Ciências da Terra. III Simpósio Nacional Sobre Ensino de Geologia no Brasil. Unicamp. Campinas. 2007. p. 383-390.

63 SILVA, Joaquim José da - Notícias sobre Cabo Negro, extrahidas dos fragmentos da viagem do doutor Joaquim José da Silva. O Patriota: Jornal Litterario, Politico, Mercantil. Rio de Janeiro. n.6, 1811. p.71-77. Extrato da viagem, que fez ao sertão de Benguella no ano de 1785 por ordem do governador e capitão general do Reino de angola, o bacharel Joaquim José da Silva, enviado aquelle reino como naturalista, e depois secretario do governo. O Patriota: Jornal Litterario, Politico, Mercantil. Rio de Janeiro. n.1, 1813. p. 97-100; n.2, 1813, p. 86-98; n.3, 1813, p. 49-60.

64 AGUIAR, José Otávio - Quando o Iluminismo Científico herborizava: Manuel Arruda da Câmara e seus escritos botânicos. Congresso Internacional Pequena Nobreza nos Impérios Ibéricos de Antigo Regime. Lisboa. 2011. Disponível em http://www.iict.pt/pequenanobreza/arquivo/Doc/p2-01.pdf. Consultado em 21/12/2011.

65 ALMEIDA, Argus Vasconcelos de; MAGALHAES, Francisco de Oliveira As "Disquisitiones" do naturalista Arruda da Câmara (1752-1811) e as relações entre a Química e a Fisiologia no final do Século das Luzes. Química Nova. vol. 20, n.4, 1997. p. 445-451. 
onde realizou pesquisas de botânica e química e foi encarregado, por D. Maria I, de organizar coleções de objetos naturais para o Real Museu do Jardim Botânico da Ajuda. As remessas de plantas enviadas do Brasil permitiram a Vandelli a inclusão de novas classificações na sua obra Flore Lusitanica et Brasileiensid specimen. ${ }^{66}$ Velloso de Miranda tem o seu nome associado à origem do Jardim Botânico de Ouro Preto, criado em $1798 .{ }^{67}$

\section{O desenvolvimento da exploração mineira no Brasil}

Os objetivos traçados pela reforma pombalina foram coroados de êxito, particularmente em relação à prospeção mineira no Brasil. A Coroa não poupou esforços para que fossem realizadas as viagens científicas orientadas para o desenvolvimento de conhecimentos de mineração e agricultura no reino e vasto império colonial. ${ }^{68} \mathrm{~A}$ formação técnica necessária aos futuros exploradores da natureza era garantida por Vandelli através de trabalhos de campo, como por exemplo os realizados na Serra da Estrela, no Mondego e na mina de Buarcos. ${ }^{69}$

Manuel Ferreira da Câmara Bethencourt Aguiar e Sá foi um estudante que se graduou bacharel em Filosofia na UC em 1788, que além de um notável naturalista também foi um influente político

66 VANDELLI, Domenico - Floræ Lusitanicæ et Brasiliensis specimen ... et Epistolae ab eruditis viris Carolo a Linné, Antonio de Haen ad Dominicum Vandelli scriptae. Conimbricae: Ex Typographia Academico-Regia, apud Bibliopolam Antonium Barneoud, 1788.

67 MAIA, Moacir Rodrigo de Castro - Uma quinta portuguesa no interior do Brasil ou a saga do ilustrado dom frei Cipriano e o jardim do antigo palácio episcopal no final do século XVIII. História, Ciências, Saúde - Manguinhos. Rio de Janeiro. V. 16, n 4. 2008, p. 881-902.

68 FigueirÔA, Sílvia F. de M.; SILVA, Clarete P.; PATACA, Ermelinda M. - Aspetos mineralógicos das "Viagens Filosóficas" pelo território brasileiro na transição do século XVIII para o século XIX. História, Ciências, Saúde Manguinhos. Rio de Janeiro. Vol 13. n 3. 2004. p. 713-729. FIGUEIROA, Silvia F. de M. - "Metais aos pés do trono": exploração mineral e o início da investigação da terra no Brasil. Revista USP [online]. 2006, n. 71, pp. 10-19.

69 FERREIRA, Martim R. Portugal Vasconcelos - 200 anos de mineralogia e arte de minas: desde a Faculdade de Filosofia (1772) até à Faculdade de Ciências e Tecnologia (1972). Coimbra: FCTUC, 1998. no Brasil, mais conhecido como o Intendente Câmara. ${ }^{70} \mathrm{O}$ seu nome está associado a vários projetos de exploração mineira no Brasil. Existem algumas incertezas sobre o local do seu nascimento. Sabe-se que era natural de Minas Gerais, muito provavelmente em Santo António de Itacambira, em territórios da Demarcação Diamantina, tendo nascido por volta de 1764. No ano de 1783 matriculou-se no curso de Leis. No ano seguinte passou a cursar também o de Filosofia. Durante os seus estudos tornou-se muito próximo de José Bonifácio de Andrada de Silva, tendo ambos um percurso muito semelhante por vários países europeus. ${ }^{71}$ Ambos foram comissionados pelo governo português para visitarem os melhores centros científicos europeus. ${ }^{72}$ Este apoio denota a importância dada à formação da elite estudantil coimbrã, oriunda do Brasil ${ }^{73} \mathrm{com}$ o objetivo de promover o desenvolvimento da exploração mineira e metalúrgica no Reino e Império Colonial. ${ }^{74}$ Ambos administraram espaços governamentais no Império português ligados diretamente à mineração e à agricultura. ${ }^{75}$

Câmara e Bonifácio foram admitidos à Real Academia das Ciências de Lisboa em 1789. Além dos seus estudos sobre a

70 VARELA, Alex Gonçalves - A atuação do naturalista Manuel Ferreira da Câmara na ilustração portuguesa: O cargo de consultor do Governo português para os assuntos de minas e metalurgia. I Simpósio de Pesquisa em Ensino e História de Ciências da Terra. III Simpósio Nacional sobre ensino de Geologia no Brasil. UNICAMP. 2007. p. 301-306.

71 VARELA, Alex Gonçalves - A trajetória do ilustrado Ferreira da Câmara em sua "fase européia" (1783-1800). Tempo. Revista do Departamento de História da UFF, v. 12. 2007. p. 165-190.

72 VARELA, Alex Gonçalves - Um manuscrito inédito do naturalista Manuel Ferreira da Câmara: "Nota sobre a extração das minas do Principado da Transilvânia” (1796). História, Ciências, Saúde - Manguinhos. Rio de Janeiro. v.17, n.1, 2010, p.185-201.

73 RODRIGUES, Manuel Augusto - A Universidade de Coimbra e a elite intelectual brasileira na última fase do período colonial. Revista de História das Ideias. Coimbra. vol. 12, 1990. p. 89-110.

74 VARELA, Alex Gonçalves - A "viagem de aperfeiçoamento técnico" de José Bonifácio e Manuel Ferreira da Câmara pelas regiões mineiras da Europa Central e Setentrional (1790-1800). Tempos Históricos. (13). 2009. p. 75-102.

75 VARELA, Alex Gonçalves - Textos em Viagem: As memórias científicas produzidas por José Bonifácio e Manuel Ferreira da Câmara (1790-1800). XIV Encontro Regional da ANPUH-Rio. Rio de Janeiro. 2010.

Disponível em http://www.encontro2010.rj.anpuh.org/resources/anais/8/1276633192_ ARQUIVO_TextoAnpuhAlexVarela2010A.pdf. Consultado em 12/12/2011. 
conservação das matas e bosques, em 1789 Câmara submeteu à Academia a Memória de Observações Fúsico-Económicas Acerca da Extração do Ouro do Brasil. A mineração foi um tema que mereceu particular destaque em várias Memórias da Academia, onde Câmara juntamente com Rodrigo de Sousa Coutinho, José Bonifácio e José Vieira Couto defenderam a recuperação mineira para o desenvolvimento económico da nação. Câmara propôs um conjunto de medidas para fomentar a exploração mineira do ferro, aço, carvão, enxofre, ouro, etc. Quando regressou ao Brasil assumiu o cargo de Intendente Geral das Minas e dos Diamantes do Distrito Diamantino e Comarca do Serro Frio. Em 1808 foi aprovada, sob a sua supervisão, a construção da fábrica de metalurgia do Morro do Gaspar Soares, nas proximidades do rio Tejuco, no Estado de Minas Gerais. ${ }^{76}$ Foi inaugurada no dia 18 de agosto de 1814, onde foi instalado o primeiro forno para a produção de ferro na América do Sul (Real Fábrica de Ferro do Morro do Pilar). ${ }^{77}$

Também José Vieira Couto era natural do Brasil. As suas origens são de uma rica região de atividades relacionadas com a exploração mineira. Nasceu em 1752 no Arraial do Tejuco, que posteriormente viria a receber o nome de Diamantina. Matriculou-se no Curso Matemático e formou-se em Filosofia pela UC, em 1778. Regressou ao Brasil em 1799, iniciando uma viagem pela Comarca do Serro do Frio, localizada ao norte da capitania de Minas Gerais, para fazer o levantamento dos recursos minerais da região, analisar a viabilidade da sua exploração económica. Nas suas prospeções procedeu à recolha de amostras de ouro, prata, ferro, cobre, chumbo, estanho, enxofre, caparrosa etc., que enviou para o Reino acompanhadas de um relatório sobre as descrições científicas e indicações da qualidade e quantidade existentes. A partir de 1803 iniciou estudos de prospeção de depósitos de salitre, ou nitrato de potassa, mineral de grande interesse estratégico por ser usado na fabricação da pólvora, e em

76 VARELA, Alex Gonçalves - Atividades científicas no Império português: um estudo da obra do 'metalurgista de profissão' Manuel Ferreira da Câmara - 1783-1820. História, Ciências, Saúde - Manguinhos. [online]. 2008, vol.15, n.4, pp. 1201-1208. 77 Primeira Fábrica de Ferro no Reino do Brasil - O Investigador Português em Inglaterra. Vol. XVII. Londres. 1816. P. 143-151.
1805 realizou prospeções de minas de cobalto. Além das remessas de salitre, também foram enviadas para Portugal sementes de plantas e outros produtos naturais. ${ }^{78}$

João da Silva Feijó (Rio de Janeiro, 1760 - Rio de Janeiro 1824) fez o reconhecimento das minas de carvão de Buarcos, na companhia de Alexandre Rodrigues Ferreira, no âmbito do estudo das produções naturais no Reino, promovidas por Vandelli. ${ }^{79}$ A permanência nas Ilhas de Cabo Verde decorreu entre 1783 e 1797, retornando nesse ano a Portugal. Durante dois anos preparou-se para uma expedição à Capitania do Ceará, onde se dedicou aos estudos de mineração, mineralogia e geologia. A provisão de D. Maria I, de 25 de fevereiro de 1799, determinava que Feijó estudasse as potencialidades naturais do Ceará. Nesta região realizou viagens a Baturité, Canindé e Serrote do Rosário. ${ }^{80}$ Durante os dois anos de preparação em Lisboa realizou estudos sobre o salitre da Ribeira de Alcântara, o que lhe conferiu a experiência necessária para os estudos que realizou sobre as minas de salitre de Tajuba. Do Ceará foram enviadas remessas de salitre com destino à refinaria de Alcântara. ${ }^{81}$

\section{A Universidade de Coimbra e o ensino das ciências no Brasil}

José Bonifácio, juntamente com Silva Pontes e Câmara Bethencourt têm os seus nomes associados à criação da Academia Real Militar do Rio de Janeiro, sob os auspícios de D. Rodrigo Domingos de Souza Coutinho, Conde de Linhares, que em 1796 assumira a Secretaria de Estado dos Negócios da Marinha e

78 FERRAZ, Márcia Helena Mendes - A produção do salitre no Brasil Colonial. Química Nova. 23(6). 2000. p. 845-850.

79 GUEDES, Maria Estela - João Silva Feijó: viagem filosófica a Cabo Verde. Asclepio. Vol. XLIX-1. 1997. p. 131-138.

80 SILVA, Clarete Paranhos da; LOPES, Maria Margaret - O ouro sob as Luzes: a 'arte' de minerar no discurso do naturalista João da Silva Feijó (1760-1824). História, Ciências, Saúde - Manguinhos. [online]. 2004, vol.11, n.3, p. 731-750.

81 SILVA, Clarete Paranhos da - As Viagens Filosóficas de João da Silva Feijó (1760-1824) no Ceará. História: Questões \& Debates, Editora UFPR. Curitiba, n 47, p. 179-201, 2007. 
Domínios Ultramarinos. Os seus projetos de desenvolvimento do Brasil ficaram plasmados na Memória sobre o melhoramento dos domínios de Sua Majestade na América. ${ }^{82}$ Para a concretização do seu plano de desenvolvimento procurou obter dos antigos estudantes das Faculdades de Filosofia e Matemática da UC o competente apoio. ${ }^{83} \mathrm{O}$ ofício de criação daquela instituição foi publicado por Carta de Lei de 4 de dezembro de $1810 .{ }^{84}$ Este documento determinava que na Academia existisse um Curso completo de Ciências Matemáticas e Ciências de Observação, das quais constava a Física, Química, Mineralogia e História Natural, que incluísse o estudo do reino vegetal e animal. Os estatutos estabeleciam que as aulas de desenho tivessem lugar no primeiro ano do curso, e no segundo ano a geometria descritiva. ${ }^{85}$ Daqui se depreende que o modelo de ensino das ciências experimentais para a formação dos futuros exploradores da natureza naquela escola brasileira tinha alguma semelhança com a organização do Curso de Filosofia e Matemática da UC. ${ }^{86}$ Mas, as influências não se limitavam apenas à estrutura do Curso. Também os privilégios e prerrogativas da Academia Real Militar eram bem explícitos quanto ao modelo inspirador: ${ }^{87}$

82 COUTINHO, D. Rodrigo de Sousa - «Memória sobre o melhoramento dos domínios de Sua Majestade na América», 1797, in Textos Políticos, Económicos e Financeiros, 1783-1811, introdução e direção de edição de Andrée Diniz da Silva, Lisboa, Banco de Portugal, 1993, tomo II. P. 47-66.

83 VARELA, Alex Gonçalves - Atividades científicas na "Bela e Barbara" Capitania de São Paulo (1796-1823). Tese (doutorado). Universidade Estadual de Campinas. Instituto de Geociências. 2005.

84 CONDE DE LINHARES - Transcrição da Carta de Lei de 4 de dezembro de 1810. Boletim da Sociedade Brasileira de Cartografia. n. 52. 2004. p. 3-13. Disponível em http://www.cartografia.org.br/boletim/Boletim52.pdf. Consultado em $4 / 01 / 2012$.

85 BUENO, Marcelo - A importância do desenho na conceção de desenvolvimento científico e tecnológico do Brasil oitocentista. Atas do Congresso Luso-Brasileiro de História das Ciências. Imprensa da Universidade de Coimbra. 2011. p. 1626-1638. 86 MORMÊLLO, Ben Hur - O ensino de matemática na Academia Real Militar do Rio de Janeiro, de 1811 a 1874. Dissertação. UNICAMP: Programa de PósGraduação em Matemática. Universidade Estadual de Campinas. Instituto de Matemática, Estatística e Computação Científica. Campinas, SP. 2010.

87 Citado em: MOREIRA, Heloi; SANTOS, Nadja Paraense dos - A Universidade de Coimbra e o Ensino de Engenharia no Brasil. Atas do Congresso Luso-Brasileiro de História das Ciências. Imprensa da Universidade de Coimbra. 2011. p. 1153-1163.
Os professores da Academia Real Militar, além do que fica expresso a seu respeito, gozarão de todos os privilégios, indultos e franquezas que tem e gozam os lentes da Universidade de Coimbra. Serão tidos e havidos como membros da Faculdade de Matemática, existente na dita Universidade, sem que entre os lentes da Academia e os de Coimbra, se haja interpor diferença alguma, ainda a respeito daquelas graças e franquezas, que requerem especial e expressiva menção, porque quero que também estes sempre se entendam e julguem compreendidos e serão considerados em tudo por tudo, como se realmente regessem suas respetivas cadeiras na mesma Universidade. Os discípulos que legitimamente frequentarem a dita Academia, gozarão dos privilégios que se concedem aos estudantes da Universidade.

Outra instituição de prestígio cuja origem e primeiros desenvolvimentos está intimamente ligada a personalidades formadas no contexto da reforma pombalina é o Museu Real do Rio de Janeiro. ${ }^{88}$ Foi fundado pelo decreto de 6 de junho de 1818 que determinava a sua instalação num prédio do Campo de Santa'Anna. Tinha como objetivo "propagar os conhecimentos e estudos das sciencias naturaes no Reino do Brazil, que encerra em si milhares de objetos dignos de observação e exame e que podem ser empregados em benefício do commércio, da indústria e das artes". ${ }^{89} \mathrm{O}$ seu primeiro diretor foi frei José Batista da Costa Azevedo, natural do Rio de Janeiro (1763-1822), antigo discípulo de Vandelli em Coimbra. ${ }^{90}$ Além de reunir um acervo disperso de História Natural, instrumentos e coleções mineralógicas,

88 Atualmente faz parte da Universidade Federal do Rio de Janeiro, conhecido como Museu Nacional.

89 SILVA, Paulo Vinícius Aprígio da Silva; KUBRUSLY, Ricardo Silva - O Archivos do Museu Nacional e a promoção do Brasil oitocentista. Anais do XXVI Simpósio Nacional de História - ANPUH • São Paulo, julho 2011. Disponível em http://www.snh2011.anpuh.org/resources/anais/14/1300569068_ARQUIVO_Oa rchivosdoMuseu NacionaleapromocaodascienciasnoBrasiloitocentista-texto.pdf. Consultado em 5/12/2011.

90 ZAVATARO, Thereza de Barcellos Baumann (coord.) - Os Diretores do Museu Nacional / UFRJ. Organizado pela Seção de Museologia. Rio de Janeiro. Museu Nacional / UFRJ. 2011. 
o novo Museu recebeu também os remanescentes anteriormente pertencentes à Casa de História Natural, criada em 1784, mais conhecida pelo nome de "Casa dos Pássaros" por possuir uma vasta coleção de pássaros empalhados. No novo Museu foram integradas a coleção mineralógica de José Bonifácio e as coleções geológicas, mineralógicas e zoológicas recolhidas por naturalistas como Georg Heinrich Graf Von Langsdorff (1774-1852), Johann Natterer (1787-1843) e Friedrich von Sellow (1789-1831). ${ }^{91}$

Regressado ao Brasil em 1819 José Bonifácio elaborou o primeiro projeto para a criação de uma Universidade no Brasil, que se pode considerar ter sido inspirada na organização da UC. Não prevendo a existência de uma Faculdade de Matemática, contudo o projeto para a Universidade a ser criada em São Paulo determinava a existência de três faculdades - Filosofia, Jurisprudência e Medicina, e teria dentre outras instalações, um Observatório Astronómico. Enquanto na UC coexistiam duas faculdades, a de Filosofia e a de Matemática, no projeto da Universidade brasileira as Ciências Matemáticas eram incorporadas na Faculdade de Filosofia com três cadeiras com uma estrutura e designação semelhante às lecionadas na Faculdade de Matemática da UC: Matemática pura, Foronomia (Ciência do Estudo Geral dos Movimentos) e Astronomia. A cadeira de Astronomia deveria estar no Colégio de Matemáticas puras e aplicadas. ${ }^{92} \mathrm{O}$ projeto para a criação desta Universidade é de finais de 1821, foi apresentada pelos deputados brasileiros pelo Estado de São Paulo à Assembleia Constituinte de Lisboa. Entre os proponentes deste projeto encontravam-se José Arouche de Toledo Rendon, Francisco Muniz Tavares, José Feliciano Fernandes Pinheiro, e António Carlos

91 FERNANDES, Antonio Carlos Sequeira Fernandes; HENRIQUES, Deise Dias Rego - José da Costa Azevedo e Custódio Alves Serrão: Da formação na Universidade de Coimbra à importante atuação na estruturação do Museu Nacional no Brasil. Atas do Congresso Luso-Brasileiro de História das Ciências. Imprensa da Universidade de Coimbra. 2011. p. 1018-1031.

92 CAMPOS, José Adolfo; SANTOS, Nadja Paraense dos - A Astronomia nas propostas de criação de Universidades no império do Brasil. Atas do Congresso Luso-Brasileiro de História das Ciências. Imprensa da Universidade de Coimbra. 2011. p. 1093-1105.
Andrada e Silva, irmão de José Bonifácio. Segundo Fernandes Pinheiro, o Tietê valia bem o Mondego do outro hemisfério. ${ }^{93}$

\section{Coimbra e o prenúncio da Independência do Brasil}

Os primeiros sinais da independência do Brasil também tiveram episódios em Coimbra. ${ }^{94}$ José Álvares Maciel, nascido no ano de 1760 em Vila Rica, atual Ouro Preto, foi condiscípulo do químico Seabra Telles. Participaram ambos nas experiências de lançamento de balões de hidrogénio, realizadas na UC em 1784. A formação de Maciel também passou pela realização de pesquisas mineralógicas na Serra da Estrela, sob a orientação de Vandelli. Depois de se formar em Filosofia, Maciel passou um ano e meio estudando química e mineralogia em Birmingham e Londres. Regressando ao Brasil foi encarregado das prospeções mineralógicas em Sabará, Caeté e Vila Rica, onde permaneceu até 1789. Viria a ser um destacado elemento do movimento independentista conhecido pela Inconfidência Mineira. Ainda em Coimbra, no final da década de 1780 começou a participar em reuniões de conspiração contra o sistema colonial português.

O ideal libertário deste movimento foi alimentado em Portugal por conceitos iluministas de ex-alunos da UC, e de ex-estudantes brasileiros de Medicina de Montpellier. Entre dezembro de 1787 e março de 1788 Maciel encontrou-se, em Coimbra com José Joaquim da Maia (que utilizava o nome de código Vendek), também ele formado em Matemática em Coimbra, no ano de 1783, e tendo continuado os seus estudos de Medicina em Montpellier em 1785, doutorando-se em 1787, onde foi contemporâneo de outro elemento da conjuração mineira, Domingos Vidal Barbosa Lage. Em Paris, Maia estabeleceu contatos com Thomas Jefferson, à época embaixador dos Estados Unidos da América em França, que lhe

93 CAMPOS, Ernesto de Souza - História da Universidade de São Paulo. Editora da Universidade de São Paulo. Edição Fac-Similar. 2004. p. 27-29.

94 MAXWELL, Kenneth - Conjuração mineira: novos aspetos. Revista Estudos Avançados [online]. 1989, vol.3, n.6, pp. 04-24. Disponível em http://www.scielo. br/pdf/ea/v3n6/v3n6a02.pdf. Consultado em 21/12/2011. 
prometera apoio dos norte-americanos às aspirações de independência que grassavam em Minas Gerais. Outros nomes da Inconfidência Mineira com ligações a Coimbra foram Tomás Antonio Gonzaga (nasceu em Miragaia, Porto, 11 de agosto de 1744 - foi deportado e morreu na Ilha de Moçambique em 1810. Era formado em Direito - 1768), Cláudio Manuel da Costa (Vila do Ribeirão do Carmo, Minas Gerais, 5 de junho de 1729. As condições da sua morte em Ouro Preto, Vila Rica, no dia 4 de julho de 1789, assassinato ou suicídio, sempre ficaram envoltas em polémica. Estudou Cânones, 1753-54), Inácio José de Alvarenga Peixoto (nascido em 1744, no Rio de Janeiro, foi deportando e morreu a 27 de agosto de 1792, em Ambaca, Angola. Formado em Direito - 1768). Luiz Antonio Furtado de Castro do Rio Mendonça e Faro (Visconde de Barbacena) frequentou a Faculdade de Filosofia a partir de 1772 e formou-se em Direito em 1778. Viria a ser Governador de Minas Gerais à época da Inconfidência Mineira e ordenou a repressão do movimento independentista. A tentativa de revolta foi abortada em 1789. Em 18 de abril de 1792 foi lida a sentença no Rio de Janeiro. Doze dos inconfidentes foram condenados à morte. Em audiência no dia seguinte, foi lido o decreto de D. Maria I pelo qual todos, à exceção de Tiradentes, tiveram a pena comutada para degredo em colónias portuguesas em África. Tiradentes foi enforcado e esquartejado no dia 21 de abril de 1792 no Campo da Lampadosa. José Álvares Maciel morreu em Massangano (Angola) em 1804. ${ }^{95}$

A Inconfidência Mineira tinha no seu programa de ação a criação de uma Universidade modelada pela de Coimbra. Nos “Autos de Devassa da Inconfidência Mineira” o depoimento de Domingos de Abreu Vieira, Tenente Coronel do Regimento de Cavalaria auxiliar de Minas Novas, foi bem explícito quanto a este propósito: em São João d'El Rei se haviam de abrir estudos, como em Coimbra, em que também se aprendessem leis. Por sua vez, o Capitão José Rezende Costa declarou que a sublevação pretendia libertar a colónia, estabelecendo também uma Universidade semelhante à de Coimbra, pelo que ficava escusado de enviar o

95 SILVA, J. Norberto de Sousa; BRAGA, Osvaldo Melo, pref. - História da Conjuração Mineira. Rio de Janeiro: Imprensa Nacional, 1948. 2t. seu filho para Portugal. Neste projeto estava previsto que o ensino das Ciências Matemáticas fosse atribuído a José Álvares Maciel. ${ }^{96}$

Fundados os estudos das ciências naturais pela Reforma Pombalina, houve que recrutar entre os seus mais destacados estudantes os que no futuro seriam docentes da Universidade. José Bonifácio de Andrada e Silva, natural de Santos, Estado de São Paulo, foi um exemplo notável entre os estudantes formados na Faculdade de Filosofia que depois foi uma dos seus mais destacados professores. Regressado à terra natal teve um papel de destaque no processo da independência do Brasil. ${ }^{97}$

José Bonifácio formou-se em Filosofia Natural e Direito Canónico, em 1787 e em 1788, respetivamente. Após a conclusão dos seus estudos em Coimbra, iniciou, em 1790, um período de estadas nos grandes centros científicos da Europa que se prolongou até 1800. Durante este período trabalhou ou conheceu os melhores institutos da França, Itália, Alemanha, Dinamarca, Holanda, Suécia, Grã-Bretanha, etc. Os seus méritos científicos permitiram-lhe ser eleito membro das Academias de Estocolmo, Copenhaga, Turim, da Sociedade dos Investigadores da Natureza de Berlim, das Sociedades de História Natural e Filomática de Paris, da Sociedade Geológica de Londres, Werneriana de Edimburgo, Mineralógica e Lineana de Jena, Filosófica de Filadélfia, etc. Foi ainda membro da Academia Imperial de Medicina do Rio de Janeiro.

$\mathrm{Na}$ capital francesa teve por mestres nos seus estudos de Química os continuadores de Lavoisier: Jean-Antoine Chaptal e Antoine-François Fourcroy. Estudou Botânica com Antoine-Laurent de Jussieu. Foi discípulo de René Just Haüy, o fundador da Mineralogia em França, aprendendo com ele Cristalografia e Mineralogia. Os seus conhecimentos em Metalurgia foram aprofundados sob a supervisão de Balthazar-Georges Sage, que, na época, era o diretor da Escola de Minas de Paris. Este naturalista, reconhecendo os dotes científicos de Andrada e Silva, incitou-o a prosseguir a sua peregrinação europeia. Na Escola de Minas de

96 CAMPOS, Ernesto de Souza - História da Universidade de São Paulo. Editora da Universidade de São Paulo. Edição Fac-Similar. 2004. p. 26.

97 MARQUES, Adílo Jorge - José Bonifácio de Andrada e Silva, Naturalista. Um lado desconhecido da Historiografia. Norte Ciência, vol. 2, n. 2. 2011. p. 59-70. 
Freiburg foi discípulo de Abraham Gottlob Werner, o mentor do neptunismo, teoria segundo a qual as rochas da crosta terrestre se tinham formado por cristalização num mar universal que cobriu toda a Terra. Nessa mesma escola, Andrada e Silva foi colega do famoso naturalista Alexander Von Humboldt, o autor de Kosmos e irmão mais novo de Wilhelm Humboldt.

Após dez anos de intensa atividade científica por toda a Europa, regressou a Coimbra, dedicando-se ao ensino da Metalurgia. ${ }^{98}$ José Bonifácio foi nomeado Intendente Geral das Minas e Metais do Reino (Carta Régia de 18/05/1801). Entre 1807 e 1820 desempenhou o cargo de Superintendente do Rio Mondego e Obras Publicas da Cidade de Coimbra com a missão de executar um programa promovido pelo governo mariano que visava aproveitar o potencial natural do Reino com vistas à sua modernização. ${ }^{99}$ Paralelamente à sua atividade docente desempenhou o cargo de Intendente Geral de Minas e Metais do Reino. Foi também Administrador das minas de carvão de Buarcos e de S. Pedro da Cova e das Reais Ferrarias da Foz de Alge, situadas num afluente do Rio Zêzere. Exerceu o cargo de Diretor do Laboratório de Docimasia da Casa da Moeda em Lisboa, onde se determinava a proporção em que os metais estavam contidos nos minérios. Foi ainda da sua responsabilidade a criação de um laboratório destinado ao apoio de prospetores mineiros em Portugal e no Brasil.

O seu nome, juntamente com o dos químicos suecos Jöns Jakob Berzelius e Johan August Arfwedson, e ainda o do francês Claude Louis Berthollet, está associado à descoberta do elemento químico lítio, o terceiro da Tabela Periódica, depois do hidrogénio e do hélio. Com efeito, foi a partir dos trabalhos publicados por estes químicos que em 1818 outro grande químico, Humphry Davy, em Inglaterra,

98 VARELA, Alex Gonçalves; LOPES, Maria Margaret; FONSECA, Maria Rachel Fróes da - As atividades do naturalista José Bonifácio de Andrada e Silva em sua 'fase portuguesa' (1780-1819). História, Ciências, Saúde - Manguinhos [online]. 2004, vol.11, n.3, p. 685-711.

99 VARELA, Alex Gonçalves - A atuação do ilustrado José Bonifácio de Andrada e Silva no cargo de Superintendente do Rio Mondego e Obras Publicas da Cidade de Coimbra (1807-1820). Anais do XXVI Simpósio Nacional de História - ANPUH • São Paulo, julho 2011. Disponível em http://www.snh2011.anpuh. org/resources/anais/14/1307388715_ARQUIVO_TextoANPUH2011AlexVarela. pdf. Consultado em 19/12/2011. aplicou a recém-descoberta técnica da eletrólise para isolar o novo elemento, a que deu o nome de lítio, do grego lithos (pedra). Andrada e Silva anunciou a descoberta de 12 novos minerais, quatro novas espécies e oito variedades de espécies conhecidas num artigo da revista alemã Allgemeines Journal Jer Chemie, publicada em 1800 em Leipzig, Entre os minerais descritos estavam a petalita e o espoduménio, que são aluminossilicatos de lítio. O artigo tinha por título (traduzido para português): Exposição sucinta das caraterísticas e das propriedades de vários minerais novos da Suécia e da Noruega, com algumas observações químicas sobre os mesmos. A importância deste trabalho justificou a sua publicação em inglês no Journal of Natural Pbylosophy, Chemistry and the Arts (1801) e em francês no Journal de Physique, de Chimie, J'Histoire Naturelle et des Arto (1800). Hoje em dia uma Galeria de Minerais, cuja origem remonta à época pombalina, no Departamento de Ciências da Terra da UC tem o nome de Andrada e Silva.

Outro Andrada e Silva notável, Martim Francisco Ribeiro de Andrada (Santos, 19-4-1775 - Santos, 23-2-1844), foi um naturalista com interesse especial pela mineração, também ele formado pela UC. Graduou-se em Filosofia e Matemática em 1798. Especializou-se em mineração tendo sido nomeado Inspetor das Minas e das Matas de São Paulo. Realizou um inventário mineralógico da província, pesquisa mais tarde complementada, com a colaboração de José Bonifácio, divulgada como apêndice do livro Geologia Elementar Aplicada à Agricultura e à Indústria. $\mathrm{O}$ inventário teve uma edição em francês com o título Amerique meridionale. Voyage mineralogique dans la province de Saint Paul, du Bresil. ${ }^{100}$ Martim Francisco chegou a Presidente da Câmara dos Deputados e Ministro da Fazenda do Império do Brasil (1822) e foi membro da Assembleia Constituinte em 1823 por São Paulo e pela mesma província deputado de 1836 a 1842.

José Bonifácio tinha retornado à sua terra natal em 1819. Ficou conhecido como o Patriarca da Independência do Brasil. A Carta que

100 VARELA, Alex Gonçalves - As viagens científicas realizadas pelo naturalista Martim Francisco Ribeiro de Andrada na capitania de São Paulo (1800-1805). Topoi. Revista de História do Programa de Pós-Graduação em História Social da UFRJ. v. 8, no 14. 2007. P. 172-205. 
escreveu a D. Pedro, datada de 1 de setembro de 1822 foi decisiva para a proclamação consumada no dia 7 de setembro. Afirmava:

Senhor. O dado está lançado: de Portugal não temos a esperar senão escravidão e horrores. Venha V.A.R. quanto antes e decida-se, porque irresoluções, e medidas d'água morna, à vista d'esse contrario que não nos poupa, para nada servem, e um momento perdido he uma desgraça. Muitas cousas terei a dizer a V.A.R., mas nem do tempo nem da cabeça posso dizer.

\section{Conclusão}

Ernesto de Souza Campos, um dos fundadores da Universidade de São Paulo e Ministro da Educação do Governo do Presidente Gaspar Dutra, considerava a UC a célula-mater de toda a cultura dos povos que falam o maravilhoso e rico idioma que Camões tanto sublinhou. ${ }^{101}$

Entrelaçou-se, portanto, a Universidade de Coimbra não somente com o reinóis, como também com os coloniais nascidos além-mar, nestas terras de um Brasil ainda em formação, como parte integrante da civilização mundial. E de lá vieram homens fundamentais de uma nova nação. Não é possível, portanto, traçar a história da educação no Brasil sem dar o devido lugar à fonte primeira de onde emanou a energia intelectual que, por evolução gradual, chegou ao sistema universitário da atual geração.

Desde os primeiros acontecimentos que conduziram à Reforma Pombalina encontramos vários episódios da História da Ciência que testemunham uma intensa relação entre a UC e o Brasil. Os arquivos documentais brasileiros e da UC reúnem fontes da História da Ciência que são um património valioso da história dos

101 CAMPOS, Ernesto de Souza - História da Universidade de São Paulo. Editora da Universidade de São Paulo. Edição Fac-Similar. 2004. p. 14. dois países. Além da concretização de um dos principais objetivos definidos pelos estatutos pombalinos - um melhor conhecimento dos recursos naturais do reino e império colonial - a UC foi também tomada como paradigma de referência para a criação das primeiras instituições de ensino superior no Brasil. Além da organização do ensino, nestas instituições viriam a ensinar antigos estudantes de Coimbra.

A UC está, em certa medida, ligada ao processo político que conduziu à independência do Brasil. Alguns dos nomes mais destacados da Inconfidência Mineira tiveram a sua formação académica em Coimbra e também aí teriam germinado algumas sementes do anseio independentista. O processo de independência culminou no dia 7 de setembro 1822 após uma intervenção decisiva de um antigo estudante e um dos mais distintos professores da Faculdade de Filosofia, o brasileiro José Bonifácio de Andrada e Silva, cientista internacionalmente reconhecido, e no Brasil conhecido como o Patriarca da Independência.

As relações científicas e culturais que ao longo dos séculos ligam a UC ao Brasil não se findaram com a proclamação da Independência da antiga colónia. O Congresso Luso-Brasileiro de História das Ciências, realizado em Coimbra entre 26 e 29 de outubro de 2011, no qual participaram mais de duas centenas de historiadores, portugueses e brasileiros, reforça a importância do Brasil para a História da Ciência na UC. Estas relações com fortes laços históricos continuam bem patentes e são a cada dia revigorados. Em novembro de 2011 a UC tinha estabelecido 124 protocolos de cooperação com instituições de ensino superior brasileiras. Ao abrigo destes protocolos estão envolvidos 940 estudantes brasileiros (321 estudantes de mobilidade/intercâmbio, 475 estudantes de mobilidade “especial” e 144 investigadores de pós-graduação) ${ }^{102}$. Além disso, o Grupo Coimbra de Universidades Brasileiras (GCUB) foi formalmente constituído em 27 de novembro de 2008. Envolvendo 52 instituições de ensino superior, garante a prosperidade das relações entre a UC e as suas congéneres brasileiras. O futuro também se constrói consolidado num longo e profícuo passado histórico.

102 Fonte da Divisão de Relações Internacionais da Universidade de Coimbra. 


\section{ESTATUTOS}

UNIVERSIDADE

D E C O I M B R A COMPILADOS DEBAIXO DA IMMEDIATA DE ELREI D. JOSÉ I. NOSSO SENHOR DE PROVIDENCIA LITERARIA CREADA PELO MESMO SENHO

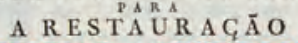
DAS SCIENCIAS, E ARTES LIBERAES NESTES REINOS, $x$ TODOS SEUS DOMINIOS POR SUA MAGESTADE NA SUA LEI DE 28 DE AGOSTO DESTE PRESENTE ANNO.
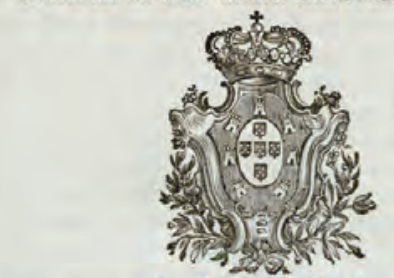

L I S B O A OFFICINA TVPOGRAFICA ANNO MDCCLXXIL
DE ORDEM DE SUA MAGESTADE. 


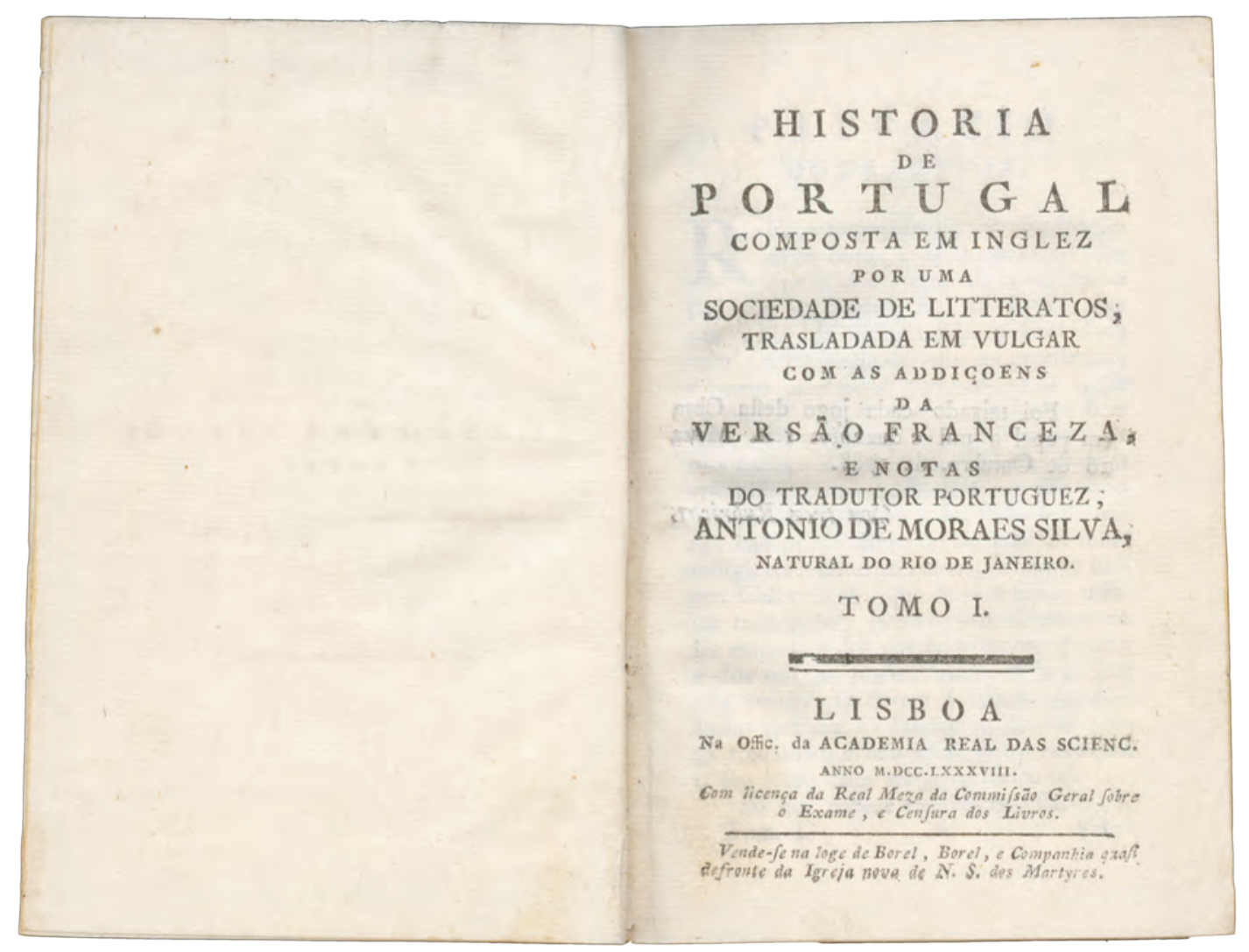

Rosto do primeiro volume da História de Portugal publicada por António de Morais e Silva (1755-1824), natural do Rio de Janeiro e formado em Leis pela Universidade de Coimbra. BGUC: 1 -(d)-2-18/20 


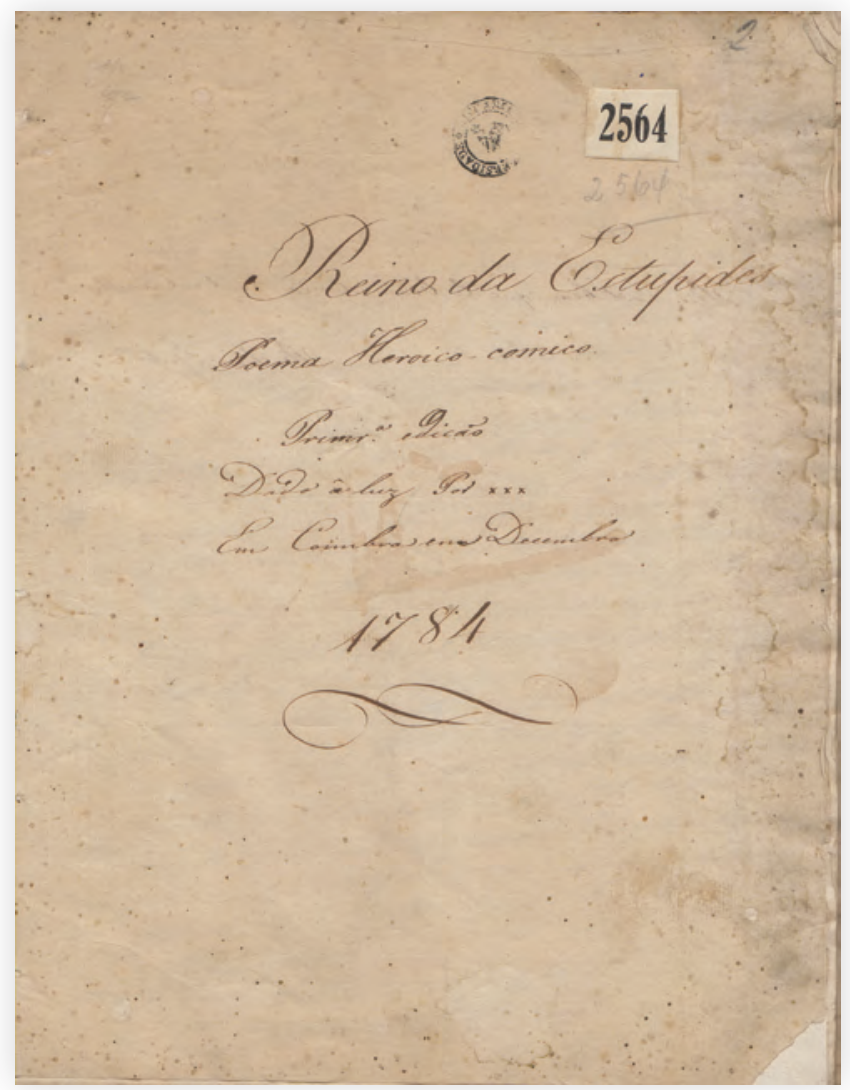

Uma das diversas cópias manuscritas do "Reino da estupidez" que inundaram Coimbra em 1782 e que José Bonifácio pode ter ajudado a copiar. Esta tem esta a curiosidade de ter uma página de título com menção "Prim. a edição" e a data de 1784. BGUC: Ms. 2564 


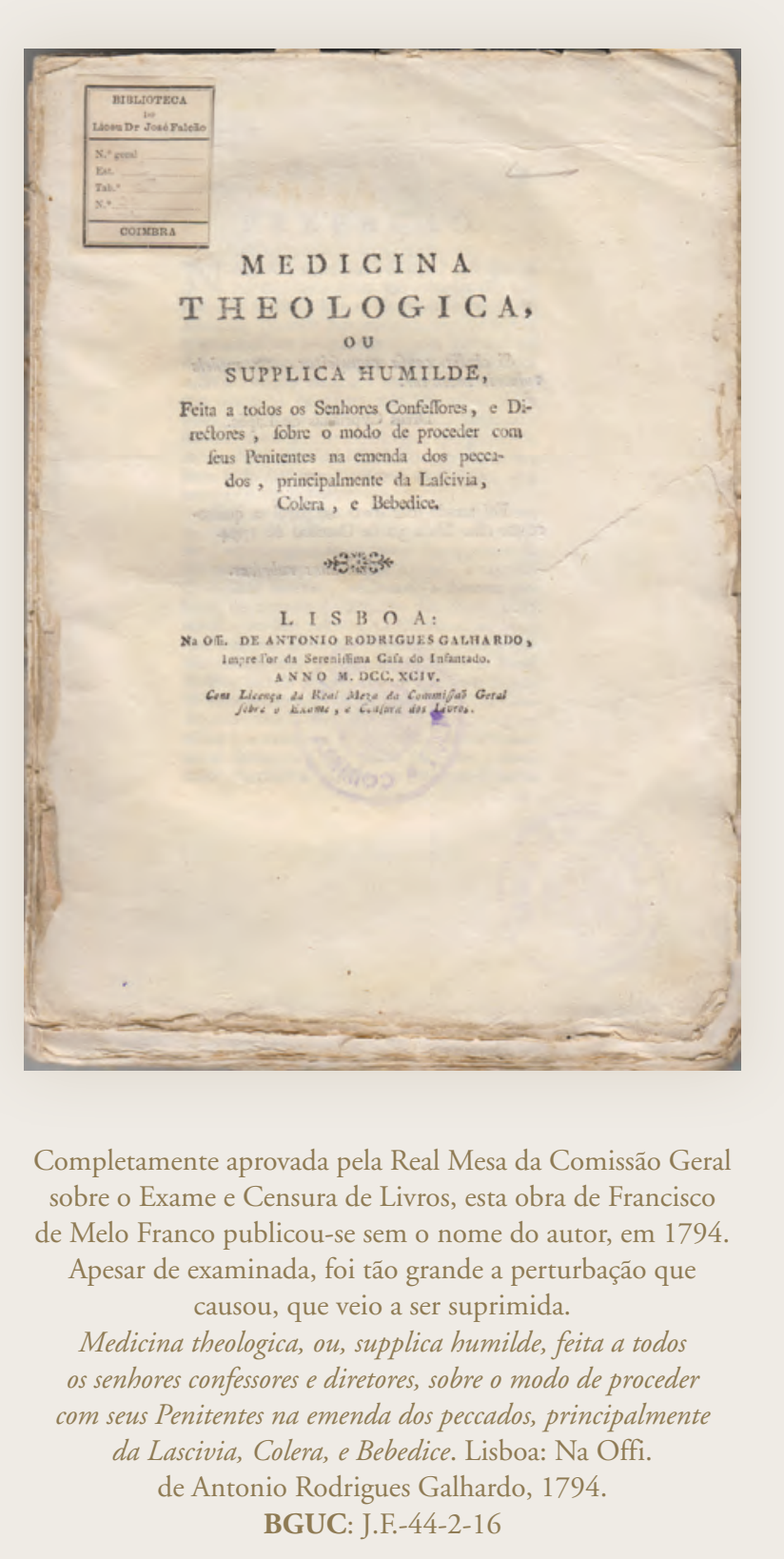




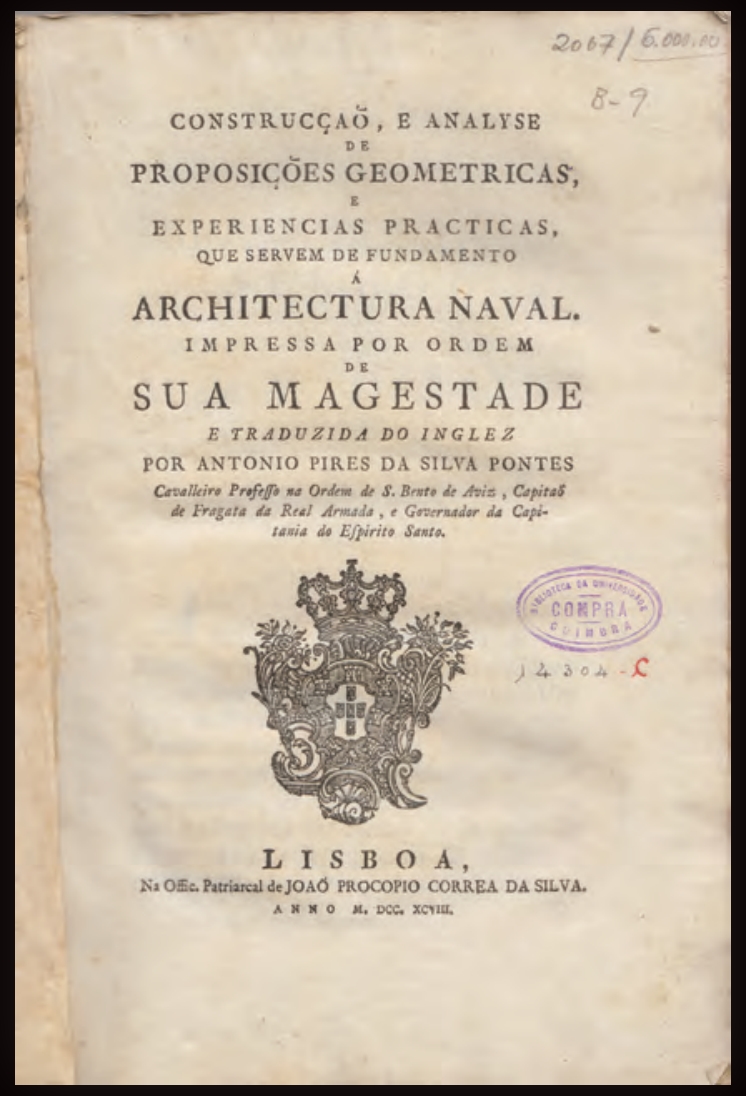

Pontes, António Pires da Silva ca. 1750/1755-1805Construção e analyse de proposiçōes geometricas, e experiencias practicas, que servem de fundamento á architectura naval... Lisboa: Offc. Patriarcal de João Procopio Correa da Silva, 1898. Disponível na Internet em http://purl.pt/11807. BGUC: RB-29-24 


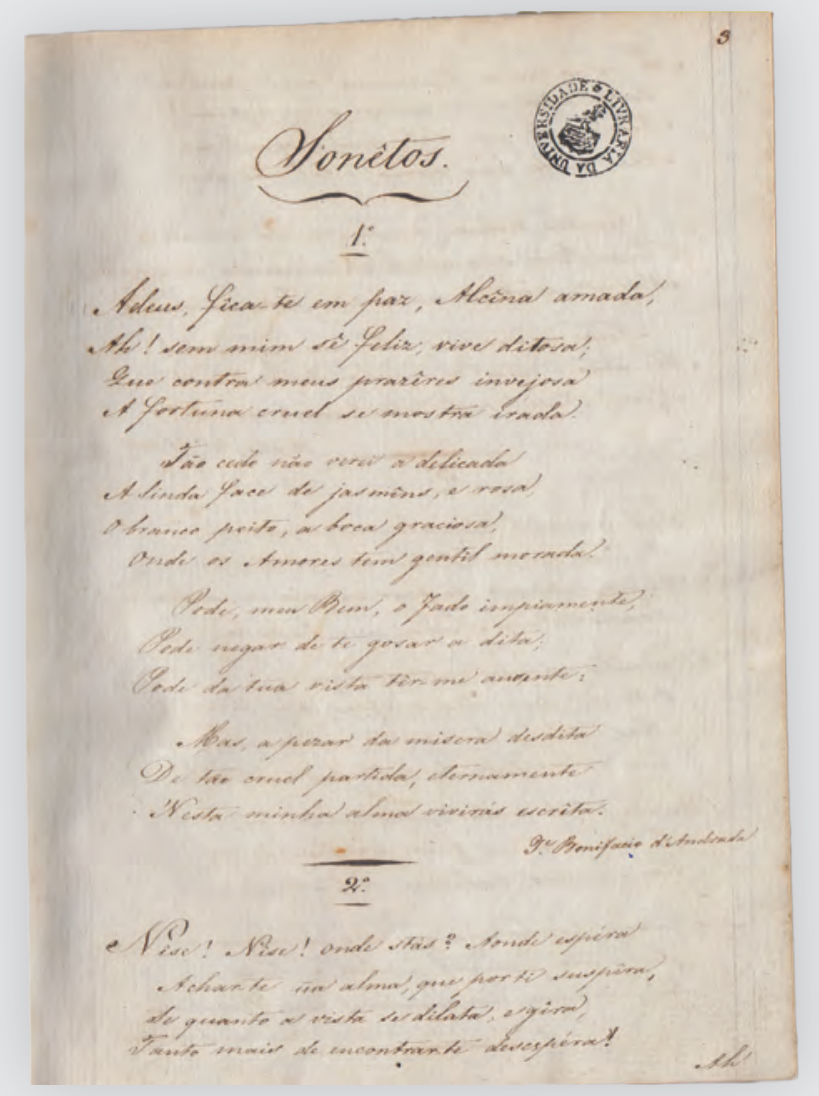

Poema de José Bonifácio que começa "Adeus, fica-te em paz Alcina amada..." incluído numa coleção manuscrita intitulada "Collecção de Peças Poéticas de Bom Gosto" (Coimbra, 1833), organizada por Miguel Justino de Araújo Gomes Álvares. BGUC: Ms. 1639 (f. 3) 
(Página deixada propositadamente em branco) 
